\title{
Turismo residencial de noreuropeos en la Costa Blanca: su manifestación territorial y estudio de casos representativos
}

\author{
Laura Domínguez Martínez \\ Universidad de Alicante \\ laura.dominguez@ua.es \\ Pablo Martí Ciriquián \\ Universidad de Alicante \\ pablo.marti@ua.es
Almudena Nolasco Cirugeda
Universidad de Alicante
almudena.nolasco@ua.es

\begin{abstract}
Turismo residencial de extranjeros en la Costa Blanca: su manifestación territorial y estudio de casos representativos (Resumen)
\end{abstract}

La costa de la provincia de Alicante, la denominada Costa Blanca, ha experimentado una importante transformación territorial en el periodo 1990 y 2010 debido, fundamentalmente, al crecimiento urbano y la considerable presencia de población noreuropea que se asienta en la zona costera con fines turísticos. En este sentido, con el objetivo de analizar las cualidades de algunos de los escenarios ocupados, se estudia tanto el proceso de ocupación como el del incremento poblacional a partir de dos tipos de datos diferentes y complementarios: por un lado, la ocupación del suelo ofrecida tanto por el proyecto CORINE (CoORdination of INformation of the Environment) como el SIOSE (Sistema de Información sobre Ocupación del Suelo de España); y por otro lado, los datos demográficos ofrecidos por el Instituto Nacional de Estadística - INE - y la Encuesta de movimientos turísticos en las fronteras FRONTUR- .

En el proceso de identificación de casos de estudio se parte de los datos globales provinciales para, en las comarcas litorales, encontrar aquellos municipios más representativos tanto del crecimiento urbano como de la concentración de población noreuropea con el fin de estudiar las principales cualidades urbanísticas de sus asentamientos. Las conclusiones constatan que el auge del turismo residencial está relacionado con un importante incremento en la ocupación de suelo y con el crecimiento de la población noreuropea. 
Además, se observa cómo las urbanizaciones estudiadas se construyen según cualidades urbanísticas concretas que utilizan tipologías arquitectónicas particulares.

Palabras clave: $u$ rbanismo, Costa Blanca, turismo residencial, dispersión urbana.

\section{Foreign residential tourism in Costa Blanca: territorial impacts and representative case studies. (Abstract)}

A considerable transformation of the territorial occupation has occurred between 1990 and 2010 in the coast of the province of Alicante - Costa Blanca-. This territorial transformation is related to a raise in the Northern European population rate.In order to analyse the coincidence of these two processes, different kinds of information are collected: on the one hand, the occupied ground surface area from both projects CORINE (CoORdination of INformation of the Environment) Land Cover and SIOSE (Information System on Land Occupation of Spain); and, on the other hand, demographic data obtained from INE (Spanish Statistical Office) and FRONTUR (Survey of tourist movements at borders) databases, among others. The identification of case studies assumes the analysis of the provincial global data and then the district data.

This approach allows figuring out which are the most representative municipalities with the highest rates of foreign population and where the largest ground occupation has occurred. Once these municipalities have been identified the aim is to describe the urban settlement characteristics. The findings of this study confirm that residential tourism is linked to urban occupation growth and the increase of Northern European population. Moreover, it is revealed that these residential areas are built according to specific patterns and architectural typologies.

Key words: Urban Studies, Costa Blanca, Residential Tourism, Urban Sprawl.

En la Comunidad Valenciana, la provincia de Alicante, ha experimentado numerosos cambios en el ámbito territorial desde 1990 hasta la actualidad. En este sentido, destaca el importante incremento de superficie artificializada $^{1}$ que multiplica entre dos y tres veces la superficie construida con anterioridad a $1990^{2}$.

Gran parte de este crecimiento se produce motivado por el importante desarrollo inmobiliario que surge en la Costa Blanca - como se denomina a la costa de la provincia de Alicante - con fines turísticos y que ha atraído a cantidad de población noreuropea a este ámbito territorial ${ }^{3}$.

Desde hace algunas décadas, la Costa Blanca se ha constituido como uno de los principales destinos turísticos de España. En la costa, la actividad turística se materializa de distintas formas sobre el territorio utilizando diferentes emplazamientos, incluso en localizaciones hacia el interior. Los visitantes se alojan de distintas formas según su motivación, el tiempo de estancia o el interés que tienen en el destino, entre otros. De esta manera, no sólo visitan la Costa Blanca turistas que compran paquetes de ocio que se consumen en cortos periodos de tiempo sino que surgen otras formas de turismo en este ámbito como es el caso del turismo residencial.

\footnotetext{
${ }^{1}$ El proyecto CORINE Land Cover, define la superficie artificializada como "Superficie de territorio que en un determinado periodo de tiempo modifica su uso original para ser ocupada directamente por el hombre para usos residenciales, comerciales, industriales, infraestructuras, de servicios públicos, de transporte, de ocio y aquellos productivos no vinculados a los usos agrarios o forestales." Por tanto, bajo el término superficie artificializada, se engloban una gran cantidad de tipologías de uso del suelo muy diferentes que responden a una categoría común que describe el suelo urbanizado.

${ }^{2}$ Agencia Europea de Medio Ambiente, 2006 y Martí y Nolasco, 2012.

${ }^{3}$ Huete y Mantecón, 2008
} 
Según Huete ${ }^{4}$, la expresión "turismo residencial" fue incorporada a la terminología académica por Francisco Jurdao en su libro España en venta: compra de suelo por extranjeros y colonización de campesinos en la Costa del Sol publicado en 1979 aunque el tema de estudio en dicha publicación - los cambios sociales que suponen la venta de suelo agrícola para la construcción de urbanizaciones turísticas adquiridas fundamentalmente por jubilados noreuropeos - había sido abordado con anterioridad por otros autores como Mario Gaviria ${ }^{5}$. Recientemente, diferentes investigadores utilizan la misma expresión para hacer referencia a variadas situaciones y procesos difíciles de delimitar, cuyo contexto se ubica en las regiones turísticas del Mediterráneo, donde coinciden la intensa actividad económica que gira en torno al negocio inmobiliario con fines turísticos y algunas de las nuevas formas migratorias y de residencialidad.

Además, Mazón y Aledo ${ }^{6}$ señalan desde la perspectiva de la producción económica del proceso turístico-residencial, que esta actividad puede definirse como "la actividad económica que se dedica a la urbanización, construcción y venta de viviendas que conforman el sector extrahotelero, cuyos usuarios las utilizan como alojamiento para veranear o residir, de forma permanente o semipermanente, fuera de sus lugares de residencia habitual""7. Ambos subrayan, además, que el turismo residencial se caracteriza, casi siempre, por la ausencia de planificación influida por los procesos de especulación del suelo.

Existen, además, otros términos utilizados en referencia a los procesos turísticos que suceden en la costa, no es tan sencillo denominar turismo residencial a un proceso complejo que surge del interés de los promotores por el comercio inmobiliario. La referencia al término "turismo inmobiliario" resulta inevitable en algunos casos, ya sea el usuario del inmueble un residencialista o un veraneante residencial ${ }^{8}$, existe una evidente demanda potencial que genera desarrollos urbano-turísticos con frecuentes problemas de estacionalidad. Así, la relación entre turismo residencial y turismo inmobiliario es muy estrecha pues el objetivo principal del primero no es generar una oferta de servicios que ponga en valor el destino como lugar turístico, sino producir suelo urbano, construir y vender viviendas. En cualquier caso, es innegable que esta forma de "vender un destino" resulta profundamente transformadora de la imagen, la estructura y el carácter de un territorio.

Si a este fenómeno unimos que el turismo se ha convertido en un producto de consumo habitual asociado a la cultura low cost, la influencia de las compañías aéreas de bajo coste, unida a la generalización del uso de internet para contratar servicios turísticos, han acabado con el monopolio de los turoperadores consiguiendo, no sólo la generalización del turismo como actividad de ocio común, sino también han propiciado el crecimiento del turismo residencial con la transformación de extensas áreas suburbanas en áreas residenciales para población, sobre todo jubilada, que permanece en su "segunda residencia" parte del año ${ }^{9}$. Aparece, entonces, una nueva

\footnotetext{
${ }^{4}$ Huete, 2009

${ }^{5}$ En publicaciones como: Gaviria, M. (1974a) «La producción neocolonialista del espacio», Papers. Revista de Sociología, no 3, 201-217 o Gaviria, M. (1974b): España a go-gó: turismo charter y neocolonialismo del espacio. Ed. Turner. Madrid, 356 pp.

${ }^{6}$ Mazón, T. y Aledo, A., en su artículo publicado (2005) "El dilema del turismo residencial: ¿turismo o desarrollo inmobiliario", en Mazón, T. y Aledo, A. (Eds.) Turismo residencial y cambio social. Nuevas perspectivas teóricas y empíricas. Aguaclara. Alicante, pp. 13-30.

${ }^{7}$ Mazón y Aledo, 2005, p. 18-19.

${ }^{8}$ Aledo explica, en La insostenibilidad del turismo residencial (2005), la diferencia que existe entre residencialista definido como aquel "usuario de vivienda turística que pasa más de seis meses al año en su segunda residencia" y el veraneante residencial que "ocupa su vivienda turística tan sólo en sus vacaciones".

${ }^{9} \mathrm{Pie}, 2013$
} 
forma de turismo capaz de consumir recursos y transformar el territorio de forma intensiva y sin precedentes.

Los jubilados noreuropeos buscan una segunda residencia en urbanizaciones turísticoresidenciales formadas por agrupaciones de chalets, adosados o bungalows en un ambiente suburbano. El interés de este colectivo por la Costa Blanca unido a la fuerte atracción que sienten los turistas extranjeros por nuestras costas, constituyen un grupo significativo de población demandante de este tipo de alojamiento, lo que contribuye determinantemente a generar una fuerte demanda de suelo y vivienda en localizaciones próximas a la costa.

Una de las consecuencias directas derivadas del proceso turístico residencial es, por tanto, el consumo desmesurado de suelo al que se ha aludido. Concretamente, la provincia de Alicante se ha visto tremendamente afectada ${ }^{10}$.

Durante las últimas décadas, este proceso de crecimiento ha estado acompañado por el incremento del número de extranjeros residentes en la provincia de Alicante y, particularmente, por el aumento de población de nacionalidad noreuropea. De forma especial, a partir del final de la década de los años 90 y a comienzos del siglo XXI, el crecimiento de población de ciertos municipios costeros se produce de paralelamente al incremento de superficie ocupada de los mismos.

Por estos motivos, resulta pertinente averiguar en qué medida el crecimiento urbano de los municipios de la Costa Blanca está relacionado con la migración de noreuropeos, analizando cuál es la influencia que este hecho tiene en su transformación.

Así, este trabajo evalúa cuantitativamente el nivel de ocupación de la franja costera de la provincia de Alicante en relación a su crecimiento poblacional para así identificar cuáles son las áreas explotadas directamente por la actividad turística residencial que, particularmente, demandan los turistas noreuropeos. Se trata de conocer, además, si existe un modelo urbanoturístico propio de este tipo de asentamientos para estudiar las cualidades comunes a su configuración urbanística y arquitectónica.

\section{La transformación territorial del litoral Mediterráneo}

El informe del Observatorio de la Sostenibilidad en España Cambios de Ocupación de Suelo en España. Implicaciones para la Sostenibilidad ${ }^{11}$ advierte sobre el importante incremento de superficie urbanizada en el territorio español — cuantificado en un 30\%-durante el periodo 1987-2000. Esta transformación resulta particularmente intensa en el litoral mediterráneo, donde destaca el crecimiento urbano de la Región de Murcia y la Comunidad Valenciana. Alicante es, precisamente, una de las provincias donde más se ha incrementado el suelo urbanizado con un aumento del 92,2 por ciento en la franja de 2 a 5 kilómetros paralela al frente costero, siendo este el máximo incremento en la ocupación de suelo que se ha producido en toda España durante el periodo mencionado. En el resto de provincias españolas el mismo valor se sitúa por debajo del $40 \%$. Por tanto, es de interés estudiar las consecuencias que este tipo de transformación conlleva a distintos niveles - económico o social, entre otros, dado que influye en las condiciones de

\footnotetext{
${ }^{10}$ Mazón, 1996.

${ }^{11}$ Jiménez, 2006. Observatorio de la Sostenibilidad en España (OSE).
} 
vida de los ciudadanos y en su entorno más directo ${ }^{12}$ — pero fundamentalmente cómo afecta a la estructura territorial.

\section{Cuadro 1}

Superficie artificializada según franjas paralelas a la costa entre 1987 y 2000

\begin{tabular}{|c|c|c|c|c|c|c|c|c|}
\hline \multirow{4}{*}{$\begin{array}{c}\text { Provincias } \\
\text { españolas }\end{array}$} & \multicolumn{4}{|c|}{ Franja de 0 a 2 kilómetros } & \multicolumn{4}{|c|}{ Franja de 2 a 5 kilómetros } \\
\hline & \multirow{3}{*}{$\begin{array}{c}\text { Superfic } \\
\text { ie total } \\
\text { (ha) }\end{array}$} & \multirow{3}{*}{$\begin{array}{c}\text { Superfic } \\
\text { ie } \\
\text { Artificia } \\
\text { l en el } \\
\text { año } \\
2000 \\
\text { (ha) }\end{array}$} & $\Delta$ & \multirow{3}{*}{$\begin{array}{c}\% \text { de } \\
\text { ocupaci } \\
\text { ón } \\
\text { artificial } \\
\text { sobre el } \\
\text { total }\end{array}$} & \multirow{3}{*}{$\begin{array}{c}\text { Superfic } \\
\text { ie total } \\
\text { (ha) }\end{array}$} & \multirow{3}{*}{$\begin{array}{c}\text { Superfic } \\
\text { ie } \\
\text { Artificia } \\
\text { l en el } \\
\text { año } \\
2000 \\
\text { (ha) }\end{array}$} & $\Delta$ & \multirow{3}{*}{$\begin{array}{c}\% \text { de } \\
\text { ocupació } \\
n \\
\text { artificial } \\
\text { sobre el } \\
\text { total }\end{array}$} \\
\hline & & & $\begin{array}{l}1987- \\
2000\end{array}$ & & & & $1987-2000$ & \\
\hline & & & $(\%)$ & & & & $(\%)$ & \\
\hline Girona & 29333 & 7070 & $0,30 \%$ & $24 \%$ & 36299 & 3274 & 11,3 & $9 \%$ \\
\hline Barcelona & 22791 & 11366 & $12,00 \%$ & $50 \%$ & 34314 & 11618 & $13,40 \%$ & $34 \%$ \\
\hline Tarragona & 35505 & 9721 & $9,00 \%$ & $27 \%$ & 47154 & 5113 & $20,70 \%$ & $11 \%$ \\
\hline Castellón & 21905 & 3732 & $46,20 \%$ & $17 \%$ & 33039 & 2173 & $34,00 \%$ & $7 \%$ \\
\hline Valencia & 21480 & 4672 & $35,10 \%$ & $22 \%$ & 31800 & 5078 & $20,80 \%$ & $16 \%$ \\
\hline Alicante & 33414 & 12629 & $40,80 \%$ & $38 \%$ & 51610 & 8047 & $92.2 \%$ & $16 \%$ \\
\hline Murcia & 30185 & 5800 & $23,30 \%$ & $19 \%$ & 37162 & 3757 & $28,10 \%$ & $10 \%$ \\
\hline Almería & 40160 & 4093 & $14,10 \%$ & $10 \%$ & 58014 & 1873 & $31,10 \%$ & $3 \%$ \\
\hline Granada & 12954 & 1191 & $24,10 \%$ & $9 \%$ & 18724 & 361 & $5,90 \%$ & $2 \%$ \\
\hline Málaga & 31316 & 13549 & $16,50 \%$ & $43 \%$ & 47836 & 6276 & $29,90 \%$ & $13 \%$ \\
\hline $\begin{array}{l}\text { Total costa } \\
\text { mediterránea }\end{array}$ & 278841 & 73823 & $19,10 \%$ & $26 \%$ & 393953 & 47569 & $28,70 \%$ & $12 \%$ \\
\hline
\end{tabular}

Fuente: Observatorio de la Sostenibilidad en España, 2006.

Algunos estudios realizados describen cómo las transformaciones territoriales en buena parte de Europa durante las últimas décadas se encuentran condicionadas por crecimientos en forma de urban sprawl ${ }^{13}$.

Este modelo de crecimiento, tal y como se especifica len el informe emitido por la Comisión Europea junto con la Agencia Europea de Medio Ambiente, caracteriza a las áreas urbanas que se desarrollan utilizando tipologías edificatorias de baja densidad, que ocupan grandes superficies constituyendo tejidos urbanos dispersos y que se articulan según una fuerte tendencia a la discontinuidad. Concretamente, si atendemos a los distintos usos del suelo que CORINE Land Cover $^{14}$ distingue para la provincia de Alicante, descubrimos que el tejido urbano discontinuo es el tipo de suelo que ocupa la mayor parte del territorio artificializado de la provincia - 40,51 por ciento (cuadro 2 ) - como ya se ha evidenciado en algunos estudios recientes ${ }^{15}$.

\footnotetext{
${ }^{12}$ Ponce, 2006

${ }^{13}$ Agencia Europea de Medio Ambiente, 2006.

${ }^{14}$ El proyecto CORINE Land Cover (CLC), iniciado en 1995 desde la Agencia Europea del Medio Ambiente tiene como objetivo obtener una base de datos europea de ocupación del suelo a escala 1:100.000, para el análisis territorial y la gestión de políticas europeas, trata de recopilar y coordinar la información sobre el medio ambiente y los recursos naturales en la Unión Europea. Instituto Geográfico Nacional.

http://www.ign.es/ign/layoutIn/corineLandCover.do

${ }^{15}$ Martí y Nolasco, 2012.
} 
En este sentido, al observar la transformación de usos del suelo urbano - continuo y discontinuo $^{16}$ — entre 1990 y 2006 en las comarcas litorales de la provincia de Alicante, podemos identificar diferentes crecimientos (cuadro 3 ).

Así, resulta especialmente interesante observar el incremento de superficie ocupada que se produce para cada uno de los mencionados usos (cuadro 2) — según el nivel 3 del CORINE Land Cover - y, particularmente, el importante crecimiento que se produce en el tejido urbano discontinuo cuyas cualidades se identifican con las del mencionado urban sprawl (cuadros 2 y $3)$.

Cuadro 2

Crecimiento entre los años 1990 y 2006 según descripción de zonas CORINE Land Cover en la provincia de Alicante

\begin{tabular}{|l|r|r|r|r|r|}
\hline \multicolumn{1}{|c|}{ TIPO DE SUELO } & \multicolumn{1}{c|}{$\begin{array}{c}\text { Superficie } \\
\text { año 1990 } \\
\text { (ha) }\end{array}$} & \multicolumn{1}{c|}{$\begin{array}{c}\text { Superficie } \\
\text { año 2006 } \\
\text { (ha) }\end{array}$} & $\begin{array}{c}\text { Incremento } \\
\text { superficie } \\
\mathbf{9 0 - 0 6}(\mathbf{h a})\end{array}$ & $\begin{array}{c}\text { Incremento } \\
\text { porcentual } \\
\text { (\%) }\end{array}$ & $\begin{array}{c}\text { Porcentaje } \\
\text { sobre el total } \\
(\mathbf{\%})\end{array}$ \\
\hline $\begin{array}{l}\text { Tejido Urbano } \\
\text { Discontinuo }\end{array}$ & $15.213,74$ & $26.348,33$ & $11.134,59$ & 73,19 & 40,51 \\
\hline Tejido Urbano Continuo & $8.608,39$ & $10.254,25$ & $1.645,86$ & 19,12 & 5,99 \\
\hline Zonas en Construcción & 848,39 & $6.739,51$ & $5.891,12$ & 694,39 & 21,43 \\
\hline $\begin{array}{l}\text { Zonas Industriales o } \\
\text { Comerciales }\end{array}$ & $2.630,73$ & $6.340,14$ & $3.709,41$ & 141,00 & 13,50 \\
\hline $\begin{array}{l}\text { Zona portuaria y } \\
\text { aeroportuaria }\end{array}$ & 357,6 & 443,6 & 86,00 & 24,05 & 0,31 \\
\hline Red ferroviaria & 821,88 & $3.273,28$ & $2.451,40$ & 298,27 & 8,92 \\
\hline Otros & 1549,71 & $4.116,78$ & $2.567,07$ & 165,65 & 9,34 \\
\hline TOTAL & $\mathbf{3 0 . 0 3 0 , 4 4}$ & $\mathbf{5 7 . 5 1 5 , 8 9}$ & $\mathbf{2 7 . 4 8 5 , 4 5}$ & $\mathbf{9 1 , 5 3}$ & $\mathbf{1 0 0}$ \\
\hline
\end{tabular}

Fuente: Elaboración propia a partir de Martí y Nolasco, 2012.

Desglosando el crecimiento que experimentan tanto el tejido urbano continuo como el discontinuo en las comarcas costeras de la provincia de Alicante con mayores crecimientos urbanísticos, la Marina Alta, la Marina Baja y la comarca del Baix Segura experimentan los incrementos más destacables.

De este modo, tal y como se observa en la figura 1 - donde se representa la ocupación del suelo en relación con la distancia respecto a la costa mediante líneas paralelas dibujadas cada kilómetro- el mayor porcentaje de suelo ocupado aparece en la franja de 0 a 5 kilómetros, perdiendo intensidad a medida que nos alejamos hacia el interior ${ }^{17}$. Se ejemplifica en este ámbito cómo la ocupación de suelo se produce en mayor medida utilizando tejido urbano discontinuo.

\footnotetext{
${ }^{16}$ El tejido urbano continuo se define como “aquél en el que la mayor parte del territorio está cubierto por estructuras y redes de transporte, edificios, carreteras y superficies artificiales cubriendo más del $80 \%$ de la superficie total." el tejido urbano discontinuo es entendido como "Edificación en bloques o con alineación al vial con o sin espacios verdes asociados, tales como y/o jardines, con calles arboladas o pequeños parques; zonas de urbanizaciones de primera o segunda residencia, a las afueras de los núcleos urbanos típicas por su fisionomía de edificaciones con espacios verdes o zonas rurales en proceso de urbanización con un alto grado de artificialización a través de la edificación." Las diferencias entre ambos tipos de tejidos son claramente identificables, ya que la característica fundamental del tejido urbano continuo es que crece apoyándose en el núcleo ya existente sobre la periferia del mismo, el crecimiento es paulatino y de menos magnitud, en cambio, el tejido urbano discontinuo se caracteriza por desarrollar un crecimiento disperso y alejado del núcleo configurando un territorio salpicado de ocupaciones, en general, de baja densidad.

${ }^{17}$ Martí, 2011
} 


\section{Cuadro 3}

Crecimiento entre los años 1990 y 2006 según descripción de zonas CORINE Land Cover en las comarcas costeras de la provincia de Alicante

\begin{tabular}{|l|r|r|r|r|}
\hline & $\begin{array}{l}\text { Superficie } \\
\text { año 1990 (ha) }\end{array}$ & $\begin{array}{l}\text { Superficie año } \\
\text { 2006 (ha) }\end{array}$ & $\begin{array}{l}\text { Incremento de } \\
\text { superficie 90- } \\
\text { 2006 (ha) }\end{array}$ & $\begin{array}{l}\text { Incremento } \\
\text { porcentual } \\
\text { (\%) }\end{array}$ \\
\hline La Marina Alta & $\mathbf{1 . 4 7 8 , 1 3}$ & $\mathbf{7 . 1 3 0 , 1 5}$ & $\mathbf{5 . 6 5 2 , 0 2}$ & $\mathbf{3 8 2 , 3 8}$ \\
\hline tejido urbano continuo & 401,67 & 820,26 & 418,59 & 104,21 \\
\hline tejido urbano discontinuo & $1.076,46$ & $6.309,89$ & $5.233,43$ & 486,17 \\
\hline La Marina Baixa & $\mathbf{7 9 5 , 5 5}$ & $\mathbf{5 . 7 7 9 , 1 1}$ & $\mathbf{4 . 9 8 3 , 5 6}$ & $\mathbf{6 2 6 , 4 3}$ \\
\hline tejido urbano continuo & 700,65 & $1.672,04$ & 971,39 & 138,64 \\
\hline tejido urbano discontinuo & 94,90 & 689,70 & 594,80 & 626,77 \\
\hline L'Alacantí & $\mathbf{4 8 7 , 9 0}$ & $\mathbf{1 . 8 9 0 , 2 4}$ & $\mathbf{1 . 4 0 2 , 3 4}$ & $\mathbf{2 8 7 , 4 2}$ \\
\hline tejido urbano continuo & 345,90 & 620,24 & 274,34 & 79,31 \\
\hline tejido urbano discontinuo & 142,00 & $1.270,00$ & $1.128,00$ & 794,37 \\
\hline El Baix Vinalopó & $\mathbf{8 0 6 , 7 5}$ & $\mathbf{1 . 7 6 4 , 5 0}$ & $\mathbf{9 5 7 , 7 5}$ & $\mathbf{1 1 8 , 7 2}$ \\
\hline tejido urbano continuo & 693,38 & $1.460,00$ & 766,62 & 110,56 \\
\hline tejido urbano discontinuo & 113,37 & 304,50 & 191,13 & 168,59 \\
\hline El Baix segura & $\mathbf{9 7 5 , 5 7}$ & $\mathbf{4 . 0 4 1 , 6 1}$ & $\mathbf{3 . 0 6 6 , 0 4}$ & $\mathbf{3 1 4 , 2 8}$ \\
\hline tejido urbano continuo & 710,59 & $2.229,16$ & $1.518,57$ & 213,71 \\
\hline tejido urbano discontinuo & 264,98 & $1.812,45$ & $1.547,47$ & 584,00 \\
\hline TOTAL & $\mathbf{4 . 5 4 3 , 9 0}$ & $\mathbf{2 0 . 6 0 5 , 6 1}$ & $\mathbf{1 6 . 0 6 1 , 7 1}$ & $\mathbf{3 5 3 , 4 7}$ \\
\hline
\end{tabular}

Fuente: CORINE Land Cover 1990-2006

\section{Figura 1}

Superficie artificializada en las comarcas costeras de la provincia de Alicante, 1990-2006

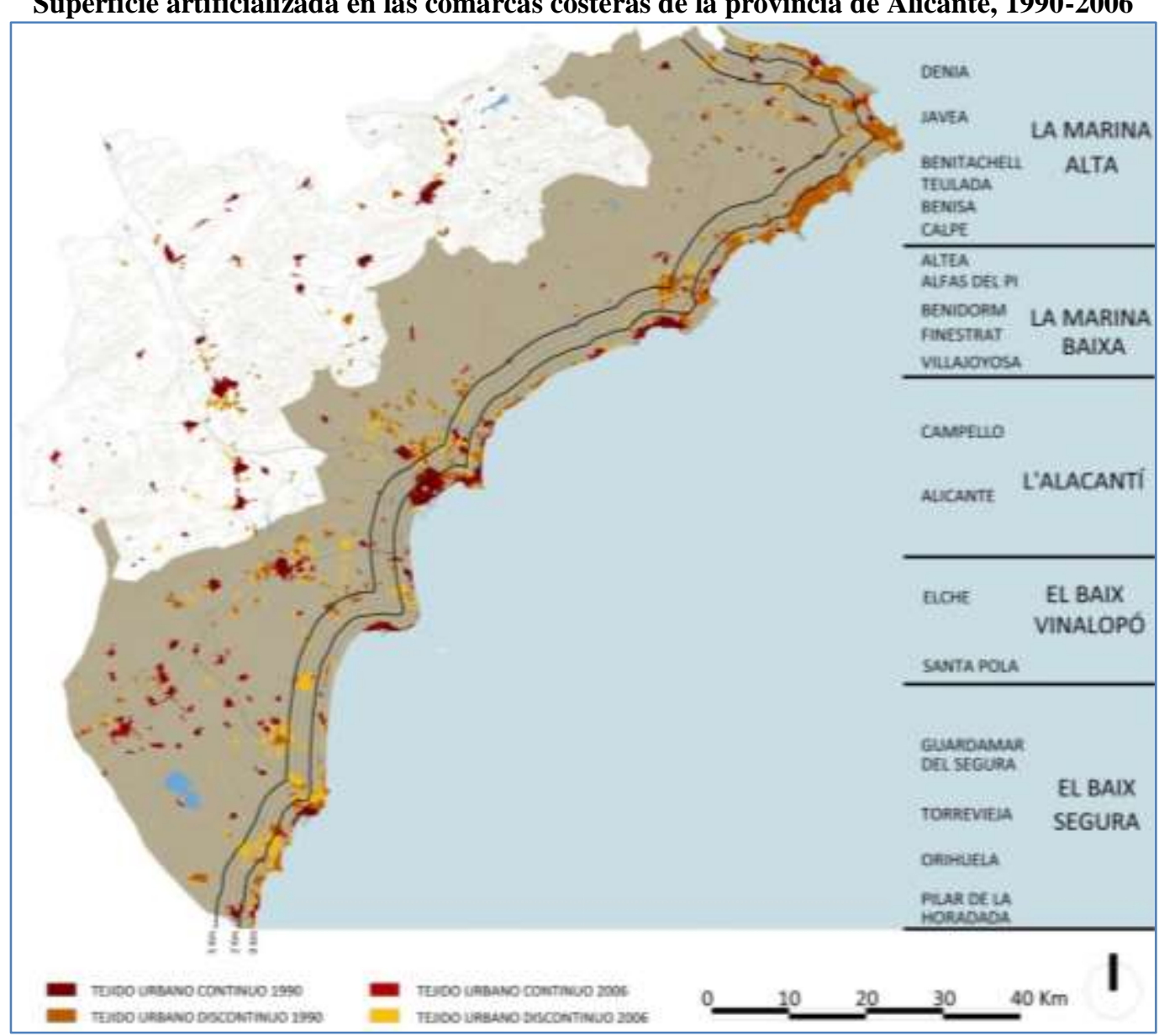

Fuente: Elaboración propia a partir del Proyecto CORINE Land Cover. 
Concretamente, la comarca de la Marina Alta —en el año 1990 - presentaba el frente costero con mayor porcentaje de suelo ocupado por tejido urbano discontinuo. Sin embargo, durante el periodo de estudio, la comarca del Baix Segura pasa a ser el entorno donde se producen los mayores crecimientos con este tipo de tejido.

Asimismo, el estudio de los crecimientos en los municipios de la provincia de Alicante, a través de los datos obtenidos por el proyecto CORINE Land Cover entre los años 1990 y 2006, muestra que el mayor incremento del tejido urbano continuo se produce en el municipio de Alicante, seguido por Elche y Orihuela donde se localizan los núcleos urbanos con mayor desarrollo económico de la provincia; mientras que, en relación al tejido urbano discontinuo, destacan las extensiones urbanizadas de los municipios de Jávea, San Miguel de Salinas o San Fulgencio, todos ellos cercanos a la costa y localizados respectivamente en las comarcas de la Marina Alta, el primero, y el Baix Segura, los demás.

\section{El turismo residencial y la población noreuropea en España y en la provincia de Alicante}

España ha sido, y sigue siendo en la actualidad, un destino turístico importante tanto en el ámbito nacional como en el internacional. Particularmente, en el caso del turismo de sol y playa, las formas de alojamiento en la costa española no dependen únicamente del modelo rotacional que es el que utilizan los viajeros que pasan cortas estancias en un destino- pues, como se ha mencionado, existe un colectivo importante de noreuropeos que llega a la Costa Blanca "para quedarse", tal y como explica Raquel Huete en su tesis doctoral ${ }^{18}$.

Los informes anuales del Instituto de Estudios Turísticos ${ }^{19}$ sobre movimientos turísticos en las fronteras - FRONTUR ${ }^{20}$ — recogen los múltiples cambios que se han producido en la recepción de turistas en España en los últimos años. Así se observa, cómo en el año 2002 España acogía a 78,9 millones de turistas extranjeros y, con el paso de los años, cómo su presencia crece hasta los 92,1 millones de turistas en 2005 para, posteriormente, a consecuencia de la crisis, decrecer fuertemente en 2006 y volver a aumentar progresiva y más lentamente hasta el año 2011, cuando se alcanzan a los 57,3 millones de turistas (cuadro 4).

El perfil sociodemográfico de los turistas que visitan España presenta diferencias, atendiendo al país de procedencia de los mismos. Según el informe FRONTUR, el Reino Unido fue el mercado emisor con más turistas que tenían por destino España - en torno al 28 por ciento del flujo total de entradas en la serie 2002-2011- junto con Alemania — en torno al 18 por ciento- (cuadro 4). Además, desde 2002 hasta 2012, la Comunidad Valenciana ha mantenido constante la atracción de turistas extranjeros en torno a 5 millones (cuadro 5) lo que posiciona a la comunidad como una de las regiones de mayor interés para el turismo internacional. Cabe destacar el alto porcentaje de turistas que prefiere el alojamiento en vivienda propia, frente a la vivienda alquilada o a la casa de familiares y amigos e incluso, en los últimos años, el despunte de este valor prefiriendo la vivienda propia frente al alojamiento hotelero.

\footnotetext{
${ }^{18}$ Huete, 2009.

${ }^{19}$ El Instituto de Estudios Turísticos, creado en 1962 y actualmente es la Subdirección General de Conocimiento y Estudios Turísticos. Se puede consultar en http://www.iet.tourspain.es/eses/elinstituto/informaciongeneral/paginas/default.aspx

${ }^{20}$ FRONTUR es la encuesta de movimientos turísticos en fronteras que recoge datos relativos a la entrada en España de visitantes no residentes en España. Se puede consultar en http://www.iet.tourspain.es/eses/estadisticas/frontur/paginas/default.aspx
} 
Cuadro 4

Total de extranjeros que llega a España anualmente y su procedencia. En millones de turistas y en porcentaje sobre el total

\begin{tabular}{|l|r|r|r|r|r|r|r|r|r|r|}
\hline ESPAÑA & \multicolumn{2}{|c|}{$\mathbf{2 0 0 2}$} & \multicolumn{2}{|c|}{$\mathbf{2 0 0 3}$} & \multicolumn{2}{|c|}{$\mathbf{2 0 0 4}$} & \multicolumn{2}{|c|}{$\mathbf{2 0 0 5}$} & \multicolumn{2}{|c|}{$\mathbf{2 0 0 6}$} \\
\hline TOTAL & 78,9 & $\%$ & 82,6 & $\%$ & 85,7 & $\%$ & 92,1 & $\%$ & 58,5 & $\%$ \\
\hline Reino Unido & 14,5 & $18 \%$ & 16,1 & $19 \%$ & 16,4 & $19 \%$ & 16,1 & $17 \%$ & 16,2 & $\mathbf{2 8 \%}$ \\
\hline Alemania & 10,1 & $13 \%$ & 9,9 & $12 \%$ & 10 & $12 \%$ & 9,9 & $11 \%$ & 10,1 & $\mathbf{1 7 \%}$ \\
\hline Francia & 8 & $10 \%$ & 7,7 & $9 \%$ & 7,5 & $9 \%$ & 8,8 & $10 \%$ & 9,2 & $16 \%$ \\
\hline Italia & 2,5 & $10 \%$ & 2,7 & $9 \%$ & 2,8 & $9 \%$ & 3,2 & $10 \%$ & 3,4 & $16 \%$ \\
\hline Otros & 43,8 & $56 \%$ & 46,2 & $17 \%$ & 49 & $17 \%$ & 54,1 & $20 \%$ & 19,6 & $21 \%$ \\
\hline
\end{tabular}

\begin{tabular}{|l|r|r|r|r|r|r|r|r|r|r|}
\hline ESPAÑA & \multicolumn{2}{|c|}{$\mathbf{2 0 0 7}$} & \multicolumn{2}{|c|}{$\mathbf{2 0 0 8}$} & \multicolumn{2}{|c|}{$\mathbf{2 0 0 9}$} & \multicolumn{2}{|c|}{$\mathbf{2 0 1 0}$} & \multicolumn{2}{|c|}{$\mathbf{2 0 1 1}$} \\
\hline TOTAL & 59 & $\%$ & 57,3 & $\%$ & 52,2 & $\%$ & 59 & $\%$ & 57,3 & $\%$ \\
\hline Reino Unido & 16,3 & $\mathbf{2 8 \%}$ & 15,8 & $\mathbf{2 8 \%}$ & 13,3 & $\mathbf{2 5 \%}$ & 16,3 & $\mathbf{2 8 \%}$ & 15,8 & $\mathbf{2 8 \%}$ \\
\hline Alemania & 10 & $\mathbf{1 7 \%}$ & 10,1 & $\mathbf{1 8 \%}$ & 8,9 & $\mathbf{1 7 \%}$ & 10 & $\mathbf{1 7 \%}$ & 10,1 & $\mathbf{1 8 \%}$ \\
\hline Francia & 9,3 & $16 \%$ & 8,2 & $14 \%$ & 7,9 & $15 \%$ & 9,3 & $16 \%$ & 8,2 & $14 \%$ \\
\hline Italia & 3,6 & $16 \%$ & 3,3 & $14 \%$ & 3,2 & $15 \%$ & 3,6 & $16 \%$ & 3,3 & $14 \%$ \\
\hline Otros & 19,8 & $22 \%$ & 19,9 & $21 \%$ & 18,9 & $24 \%$ & 19,8 & $22 \%$ & 19,9 & $21 \%$ \\
\hline
\end{tabular}

Fuente: FRONTUR 2002-2011

Cuadro 5

Modalidad de alojamiento de turistas internacionales en la Comunidad Valenciana (millones de turistas)

\begin{tabular}{|l|r|r|r|r|r|r|r|r|r|r|r|}
\hline C.VALENCIANA & $\mathbf{2 0 0 2}$ & $\mathbf{2 0 0 3}$ & $\mathbf{2 0 0 4}$ & $\mathbf{2 0 0 5}$ & $\mathbf{2 0 0 6}$ & $\mathbf{2 0 0 7}$ & $\mathbf{2 0 0 8}$ & $\mathbf{2 0 0 9}$ & $\mathbf{2 0 1 0}$ & $\mathbf{2 0 1 1}$ & $\mathbf{2 0 1 2}$ \\
\hline TOTAL & 4,9 & 4,9 & 4,9 & 5,1 & 5,5 & 5,6 & 5,7 & 5,1 & 5,0 & 5,4 & 5,3 \\
\hline Extrahoteleros & 2,9 & 2,8 & 2,9 & 3,2 & 3,6 & 3,6 & 3,6 & 3,3 & 3,3 & 3,5 & 3,3 \\
\hline Vivienda propia & 1,8 & 1,8 & 1,9 & 2,1 & 2,4 & 2,5 & 2,5 & 2,29 & 2,3 & 2,5 & 2,4 \\
\hline Vivienda alquilada & 0,8 & 0,87 & 0,74 & 0,7 & 0,8 & 0,7 & 0,7 & 0,6 & 0,6 & 0,8 & 0,7 \\
\hline Otros & 0,3 & 0,23 & 0,5 & 0,3 & 0,3 & 0,3 & 0,3 & 0,3 & 0,28 & 0,2 & 0,2 \\
\hline Hoteleros & 2,0 & 2,1 & 2,0 & 1,9 & 1,9 & 2,0 & 2,1 & 1,8 & 1,7 & 1,9 & 2,0 \\
\hline
\end{tabular}

Fuente: FRONTUR 2002-2012

Todos estos datos vienen a confirmar un considerable interés internacional en España como destino turístico y, particularmente, la preferencia por parte de los turistas noreuropeos.

También es cierto que, con el fin de profundizar en la distribución de los noreuropeos residentes en España, es preciso estudiar además los datos del Padrón Municipal que permiten establecer una valoración más precisa de la distribución de la población foránea en España.

En este sentido, los datos del Padrón Municipal del año $2010^{21}$ muestran el alto porcentaje de población noreuropea empadronada en la provincia de Alicante - alcanzando el 24 por ciento que suponen 467.099 habitantes - seguida de Baleares, Almería y Girona con un 22 por ciento de foráneos (figura 2). De este modo, las provincias con mayor cantidad de extranjeros empadronados se encuentran ubicadas en la costa mediterránea, disminuyendo notablemente dicha población conforme nos acercamos al frente oceánico o al mar cantábrico, ya que todas las provincias del norte, el interior y el sur de la península, ofrecen valores mínimos de presencia extranjera, como sucede en Córdoba, Badajoz o A Coruña con un 3 por ciento respectivamente. Esta tendencia ya la evidencia Ernesto Cutillas en el año 2006 en su investigación sobre $E l$

\footnotetext{
${ }^{21}$ Instituto Nacional de Estadística (INE), 2010.
} 
incremento de la población extranjera en la provincia de Alicante. Los contrastes en su distribución espacial ${ }^{22}$.

Figura 2

Porcentaje de extranjeros sobre población empadronada en España

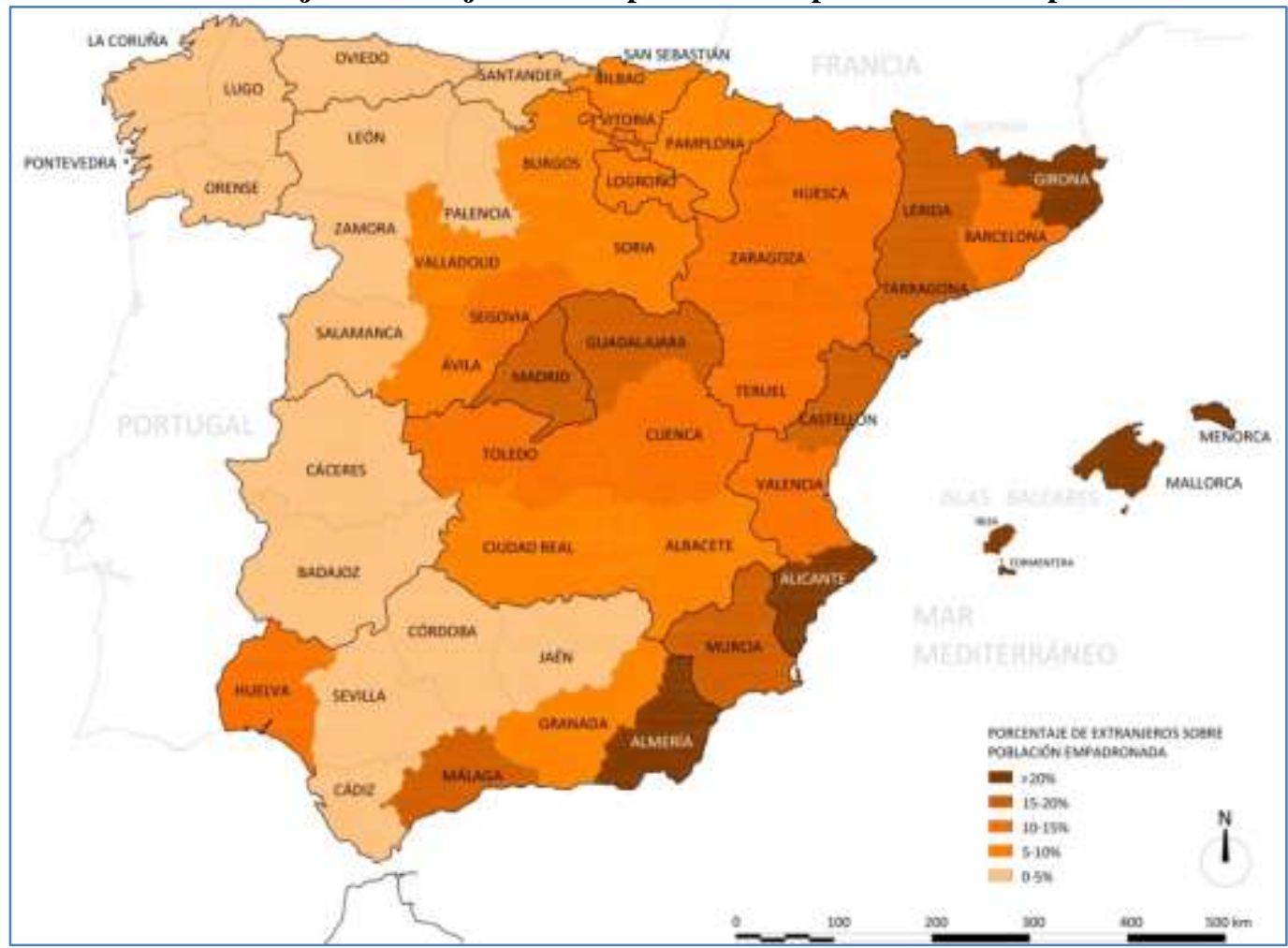

Fuente: Elaboración propia a partir del Padrón municipal de 2010, INE.

Por tanto, la distribución de la población foránea sobre la península ibérica se produce de forma desigual. Un hecho significativo de este proceso, tras el análisis de los datos, es que las provincias españolas con mayor porcentaje de extranjeros empadronados no coinciden necesariamente con aquellas con mayor presencia noreuropea. La relevancia de estos datos no es cuantitativa sino que lo realmente destacable es su reparto, puesto que los extranjeros empadronados se distribuyen por el territorio de manera bien diferenciada. Por un lado, las grandes capitales como Madrid o Barcelona siguen siendo las que atraen a mayor cantidad de extranjeros con nacionalidades más diversas, manteniendo las estadísticas de años anteriores ${ }^{23}$, mientras que, por otro lado, destacan provincias como Alicante, Baleares y Murcia, donde existe una mayor presencia de noreuropeos. (cuadro 6)

De acuerdo con las fuentes examinadas, la provincia de Alicante es uno de los destinos más atractivos para los turistas noreuropeos y, además, es la que mayor porcentaje de población extranjera empadronada tiene. Estratégicamente, los noreuropeos seleccionan como principal destino aquellas provincias que mejor satisfacen sus necesidades en el momento de la migración $\mathrm{y}$, a la vista de los datos, muchos de los que establecen su residencia en el litoral alicantino, lo hacen atraídos por "el clima, el sol y la playa, la familiaridad del destino, diversos factores

\footnotetext{
${ }^{22}$ Cutillas, 2009.

${ }^{23}$ Observatorio Valenciano de la Vivienda, 2006.
} 
económicos, las relaciones familiares y sociales", así como la amplia oferta de alojamiento que incluye desde hoteles hasta viviendas en propiedad ${ }^{24}$.

\section{Cuadro 6}

Comunidades y provincias españolas con mayor relación entre extranjeros y población total en España 2010 según sus nacionalidades de procedencia

\begin{tabular}{|l|r|r|r|r|r|r|r|r|}
\cline { 2 - 9 } \multicolumn{1}{c|}{} & \multicolumn{1}{c|}{$\begin{array}{c}\text { Total } \\
\text { Extranjeros }\end{array}$} & $\begin{array}{c}\text { Total } \\
\text { Población }\end{array}$ & Porcentaje & Marruecos & $\begin{array}{l}\text { Reino } \\
\text { Unido }\end{array}$ & Ecuador & Colombia & Alemania \\
\hline $\begin{array}{l}\text { COMUNITAT } \\
\text { VALENCIANA }\end{array}$ & 893.759 & 5.111 .706 & $17 \%$ & 75.702 & 144.078 & 48.314 & 43.043 & 43.249 \\
\hline Alicante & $\mathbf{4 6 7 . 0 9 9}$ & $\mathbf{1 . 9 2 6 . 2 8 5}$ & $\mathbf{2 4 \%}$ & 34.267 & 130.302 & 21.683 & 19.278 & 36.543 \\
\hline Castellón & 112.265 & 604.274 & $19 \%$ & 18.245 & 1.978 & 2.116 & 4.540 & 1.914 \\
\hline Valencia & 314.395 & 2.581 .147 & $12 \%$ & 23.190 & 11.798 & 24.515 & 19.225 & 4.792 \\
\hline $\begin{array}{l}\text { ILLES } \\
\text { BALEARS }\end{array}$ & 242.256 & 1.106 .049 & $22 \%$ & 23.922 & 23.561 & 13.152 & 10.224 & 36.003 \\
\hline ANDALUCIA & 704.056 & 8.370 .975 & $8 \%$ & 111.867 & 113.654 & 22.394 & 22.492 & 26.940 \\
\hline Almería & $\mathbf{1 5 1 . 1 5 9}$ & $\mathbf{6 9 5 . 5 6 0}$ & $\mathbf{2 2 \%}$ & 41.647 & 21.090 & 6.422 & 2.828 & 2.876 \\
\hline Málaga & 275.027 & 1.609 .557 & $17 \%$ & 27.631 & 70.781 & 4.938 & 6.868 & 16.359 \\
\hline CATALUNA & 1.198 .538 & 7.512 .381 & $16 \%$ & 233.954 & 21.775 & 78.796 & 48.847 & 24.032 \\
\hline Barcelona & 805.487 & 5.511 .147 & $15 \%$ & 139.736 & 12.366 & 69.687 & 33.474 & 15.164 \\
\hline Girona & $\mathbf{1 6 2 . 2 4 7}$ & $\mathbf{7 5 3 . 0 4 6}$ & $\mathbf{2 2 \%}$ & 39.137 & 4.323 & 3.251 & 4.841 & 5.069 \\
\hline Lleida & 80.490 & 439.768 & $18 \%$ & 15.416 & 284 & 1.569 & 3.299 & 294 \\
\hline Tarragona & 150.314 & 808.420 & $19 \%$ & 39.665 & 4.802 & 4.289 & 7.233 & 3.505 \\
\hline $\begin{array}{l}\text { REGION DE } \\
\text { MURCIA }\end{array}$ & 241.865 & 1.461 .979 & $17 \%$ & 68925 & 22380 & 45599 & 7185 & 3494 \\
\hline
\end{tabular}

Fuente: Instituto Nacional de Estadística. Patrón municipal a 1-01-2010. Elaboración propia.

El reparto geográfico de extranjeros en la provincia de Alicante, al igual que sucede a escala estatal, se produce de manera desigual, puesto que este colectivo se asienta en mayor medida en los municipios litorales y prelitorales (figura 3).

En el año 2010, Torrevieja es el municipio alicantino con mayor presencia extranjera: 53.332 habitantes empadronados (el 53 por ciento de su población), seguido de Alicante, 50.331 (15\%) y Orihuela $35.876(41 \%)$, que son los de mayor ocupación costera, tal y como hemos visto anteriormente. Cada municipio da respuesta a un motivo de la migración. Alicante, por ejemplo, ha sido y es la capital administrativa y funcional de toda la provincia, es por ello que capta la atención de los migrantes que buscan empleo con la finalidad de alcanzar mayores oportunidades. En cambio, ciudades como Orihuela o Torrevieja tienen como principal motivo de atracción tanto la situación laboral como la turística, puesto que ambas ciudades desarrollan una economía basada en el turismo residencial y en la agricultura, con un sistema agrario muy peculiar. También destacan por la alta concentración de habitantes de origen extranjero empadronados, Dénia, Jávea o Elche por delante de municipios como Calpe, Alfás del Pi, Benidorm, Rojales o Pilar de la Horadada.

Teniendo en cuenta que el presente estudio trata de establecer una relación entre los municipios donde se produce un importante crecimiento en la ocupación del suelo y el incremento poblacional de noreuropeos, resulta pertinente conocer también qué municipios son los seleccionados por los noreuropeos para establecer su residencia con fines turísticos.

\footnotetext{
${ }^{24}$ Cutillas, 2009.
} 
Según el Informe del Observatorio Valenciano de la Vivienda (OVV) titulado Segunda Residencia y turismo residencial en la Comunidad Valenciana, un turista de segunda residencia, es aquel que, "tiende a pasar más tiempo en el destino turístico, repartido, generalmente, en varias visitas anuales". Sin embargo, el turista residencial, es aquel que "convierte su segunda residencia en residencia permanente, y su permanencia en el destino puede, pues, superar el año. Sin embargo, no realiza actividad económica en el destino turístico. El impacto que tiene es mayor en el ámbito social, cultural, medioambiental, económico y político, porque se incorpora a la residencia habitual, pero con necesidades de servicios y equipamientos similares a los de la población residente" ${ }^{25}$. En el caso que nos ocupa, ambos tipos de turistas nos interesan porque independientemente de su motivación o tiempo dedicado a permanecer en el destino pueden influir en el crecimiento tanto poblacional como de la ocupación del suelo.

\section{Figura 3}

Empadronamiento de extranjeros en la provincia de Alicante

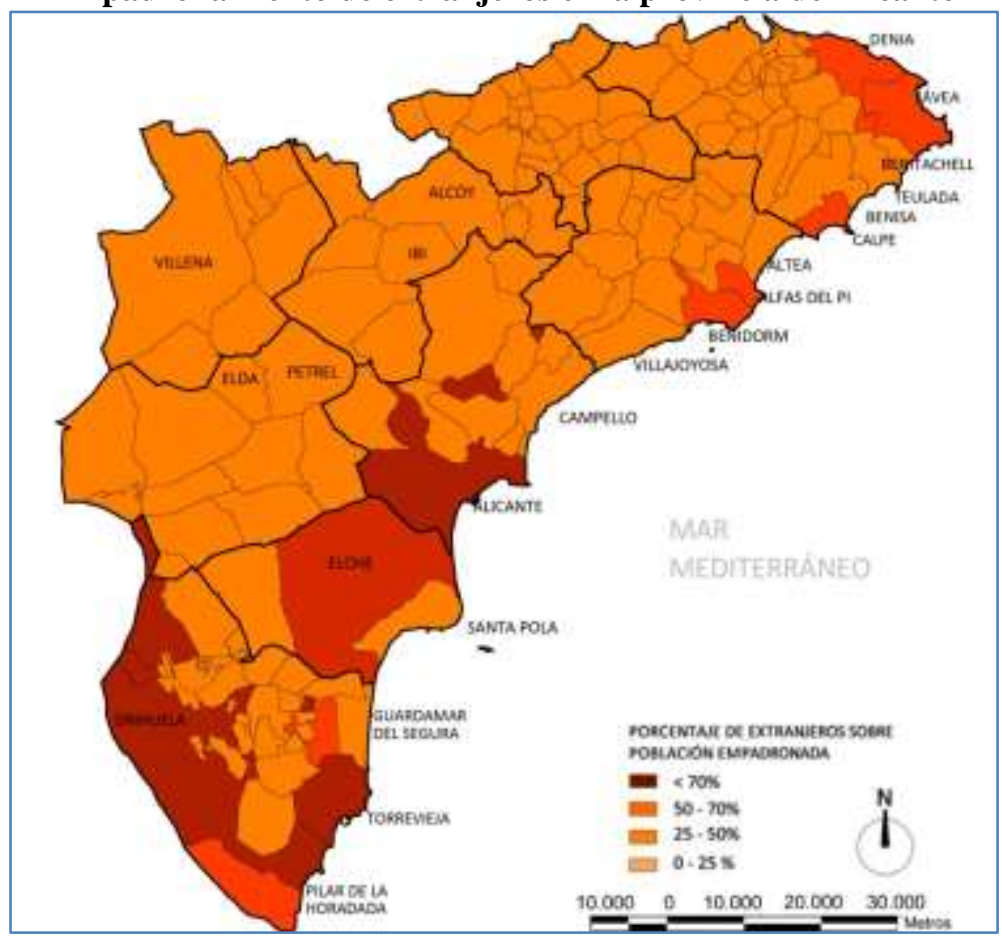

Fuente: Elaboración propia a partir del Padrón municipal de 2010, INE.

De este modo, se observa cuál es el porcentaje de extranjeros empadronados en una población respecto de la totalidad de habitantes que residen en la misma con el fin de distinguir cuántos noreuropeos residen en los municipios costeros. Los resultados que se obtienen de este análisis resultan muy interesantes.

La primera singularidad a destacar es la importante presencia de extranjeros tanto en el norte como en el sur de la provincia, prefiriendo siempre la franja costera a la de interior. En este caso, se concentra mayor cantidad de extranjeros al norte y al sur de la provincia en las comarcas de la Marina Alta, el Baix Segura y la Marina Baja, aunque en menor medida (figura 3). En la comarca de la Marina Alta, destaca el municipio de Benitachell con un 70 por ciento de población extranjera empadronada - sobre un total 5.488 habitantes 3.867 extranjeros, que provienen principalmente de Reino Unido (2.214 habitantes) y Alemania (584 habitantes) - . En el Baix Segura, el municipio de San Fulgencio aloja un 78 por ciento de población extranjera empadronada — con 6.187 habitantes procedentes de Reino Unido y 1.430 de Alemania — y en

\footnotetext{
${ }^{25}$ Observatorio Valenciano de la Vivienda, 2006.
} 
el municipio de Rojales reside un 76 por ciento de población extranjera empadronada sobre el total — donde 8.840 proceden de Reino Unido y 1.563 de Alemania-. En contraste con los datos anteriormente citados, en las comarcas del interior de la provincia - El Comptat, L'Alcoià, L'Alt Vinalop y el Vinalopó Mitjà- y en las comarcas costeras de l'Alacantí y del Baix Vinalopó, apenas se alcanza el 14 por ciento de población extranjera empadronada. Por tanto, resulta evidente como en algunos municipios de la Costa Blanca existe una fuerte concentración de población noreuropea empadronada que se aloja de forma más o menos permanente constatando la existencia del turismo residencial en municipios costeros o próximos a la costa. Falta averiguar si esta presencia está relacionada con el importante incremento en la ocupación de suelo que en las últimas décadas se ha producido en este mismo ámbito territorial.

Figura 4

Porcentaje de extranjeros sobre población empadronada en la provincia de Alicante

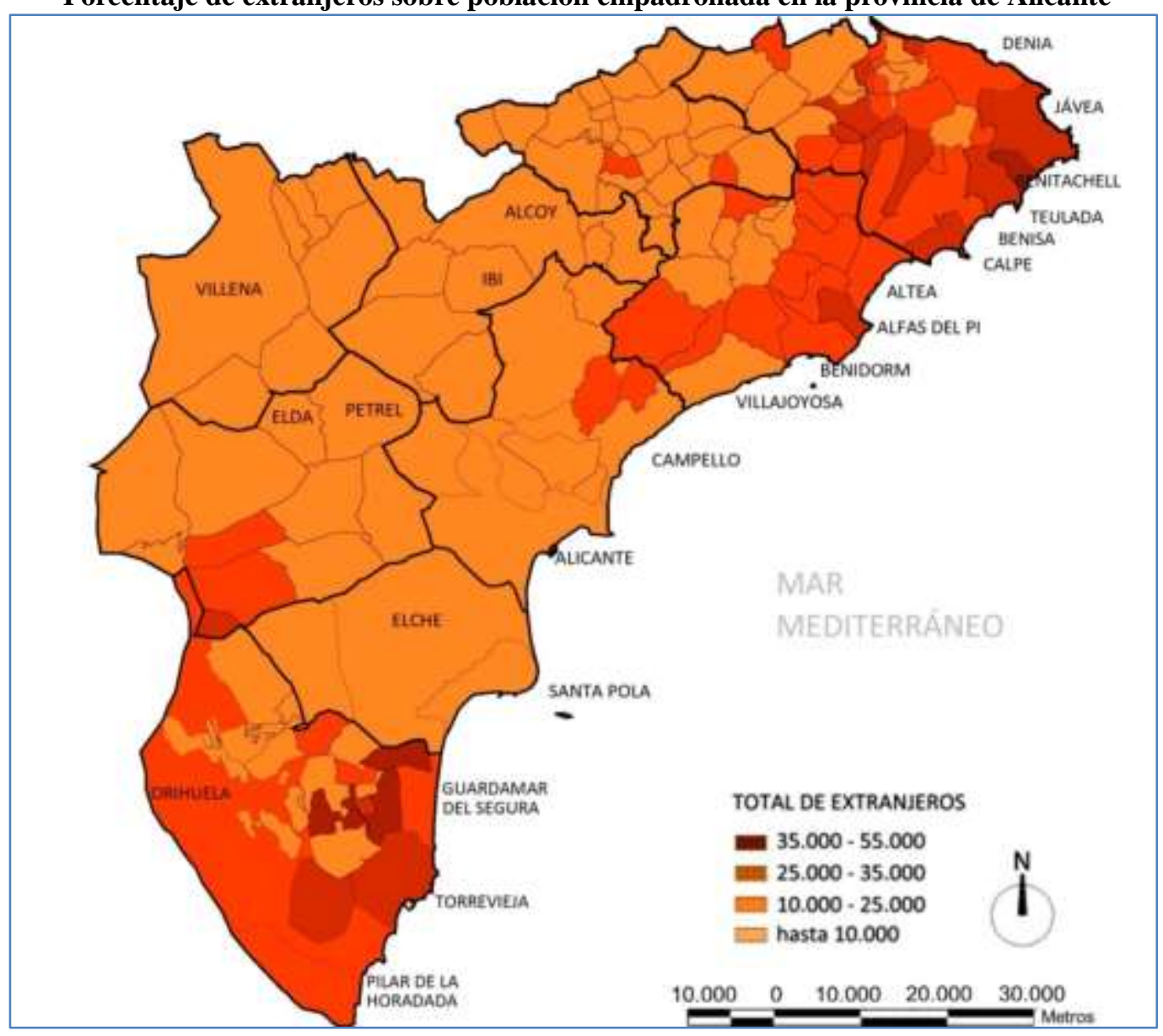

Fuente: Elaboración propia a partir del Padrón municipal de 2010, INE.

\section{Presencia noreuropea e incremento de superficie construida sobre las comarcas costeras de la provincia de Alicante}

En estudios previos se defiende que la vinculación de los noreuropeos a las comarcas costeras no es azarosa ya que tanto el tipo de turista como el modelo de asentamiento en el territorio, se produce de maneras distintas. En este caso, se detalla exclusivamente la situación de las dos comarcas que mayor presencia de extranjeros empadronados tienen en toda la provincia (figura 4) - la Marina Alta, en el límite norte de la provincia, y el Baix Segura, en el extremo sur-. 


\section{El caso de la Marina Alta y del Baix Segura}

La distribución de los extranjeros en las comarcas de la Marina Alta y del Baix Segura, confirma que no se localizan exclusivamente en municipios del frente litoral, sino que también residen en los situados al interior. El porcentaje de extranjeros que habita en ambas comarcas llega a superar, en muchas ocasiones, a la cantidad de población originaria del municipio como sucede en las poblaciones de San Fulgencio, Rojales, San Miguel de Salinas o Poblenou de Benitachell.

En la comarca de la Marina Alta, los municipios más poblados son Dénia, capital de la comarca, que cuenta con 44.498 habitantes $^{26}$ — de los que 13.586 son extranjeros — seguido por Jávea 31.909 habitantes de los que 17.414 extranjeros - y Calpe -29.909 habitantes de los que 18.873 extranjeros - . Sin embargo, los datos más relevantes se obtienen al observar la cantidad de extranjeros empadronados respecto a la población autóctona, como sucede en municipios como Benitachell o Llíber, donde la población extranjera empadronada supera a la autóctona en un 70 por ciento para el primer caso y un 67 por ciento en el segundo. Concretamente, en el caso de Benitachell de 5.488 habitantes, 3.867 son extranjeros.

Las nacionalidades de procedencia que mayor presencia tienen entre los extranjeros empadronados en la comarca de la Marina Alta, son la británica y la alemana, predominando los primeros en todos los municipios excepto en Calpe y en Els Poblets donde la población extranjera es principalmente Alemana. (cuadro 7 y figura 5)

Cuadro 7

Municipios con mayor presencia extranjera empadronada y sus nacionalidades, en la comarca de la Marina Alta. Año 2010

\begin{tabular}{|c|c|c|c|c|c|c|c|c|}
\hline \multirow[t]{2}{*}{ Municipio } & \multicolumn{3}{|c|}{2010} & \multicolumn{5}{|c|}{ Procedencia } \\
\hline & Extranjeros & \begin{tabular}{|c|} 
Total \\
habitantes \\
\end{tabular} & \%Extr. & Reino Unido & Alemania & Colombia & Marruecos & Ecuador \\
\hline Jávea & 17414 & 31909 & $55 \%$ & 8323 & 2113 & 742 & 703 & 403 \\
\hline Benitachell & 3867 & 5488 & $70 \%$ & 2214 & 584 & 28 & 59 & 40 \\
\hline Teulada & 9829 & 14778 & $67 \%$ & 3998 & 1822 & 351 & 274 & 85 \\
\hline Calpe & 18873 & 29909 & $63 \%$ & 4462 & 3950 & 492 & 659 & 53 \\
\hline Poblets, Els & 2073 & 3310 & $63 \%$ & 428 & 924 & 29 & 18 & 3 \\
\hline Llíber & 707 & 1056 & $67 \%$ & 470 & 115 & 0 & 1 & 0 \\
\hline Ràfal D'almunia & 375 & 726 & $52 \%$ & 229 & 61 & 1 & 4 & 8 \\
\hline Alcalí & 931 & 1524 & $61 \%$ & 684 & 55 & 1 & 4 & 10 \\
\hline Murla & 332 & 629 & $53 \%$ & 242 & 17 & 1 & 1 & 1 \\
\hline Orba & 1490 & 2629 & $57 \%$ & 968 & 204 & 2 & 10 & 17 \\
\hline
\end{tabular}

Fuente: Instituto Nacional de Estadística. Padrón municipal a 1-01-2010. Elaboración propia.

Desde el punto de vista de los crecimientos del suelo, la Marina Alta es una comarca que en el año 1990 ya tenía edificada gran parte de la franja litoral y prelitoral, por lo que los incrementos de superficie construida hasta 2006 - según datos de ocupación en base al proyecto CORINE Land Cover - no son relevantes. Sí es cierto que los mayores crecimientos de tejido urbano continuo, se localizan en Dénia y Jávea — con crecimientos superiores al 60\%, pasando de 125 hectáreas construidas a 207 hectáreas y de 124 ha a 209 ha, respectivamente-y, en cuanto a

\footnotetext{
${ }^{26}$ Datos del Instituto Nacional de Estadística (INE), 2010.
} 
tejido urbano discontinuo Benitachell es uno de los que tiene un mayor crecimiento - pasando de 9,8 ha a 383,6 ha-, junto con Els Poblets — que crece de 19 ha a 558,4 ha- (figura 6).

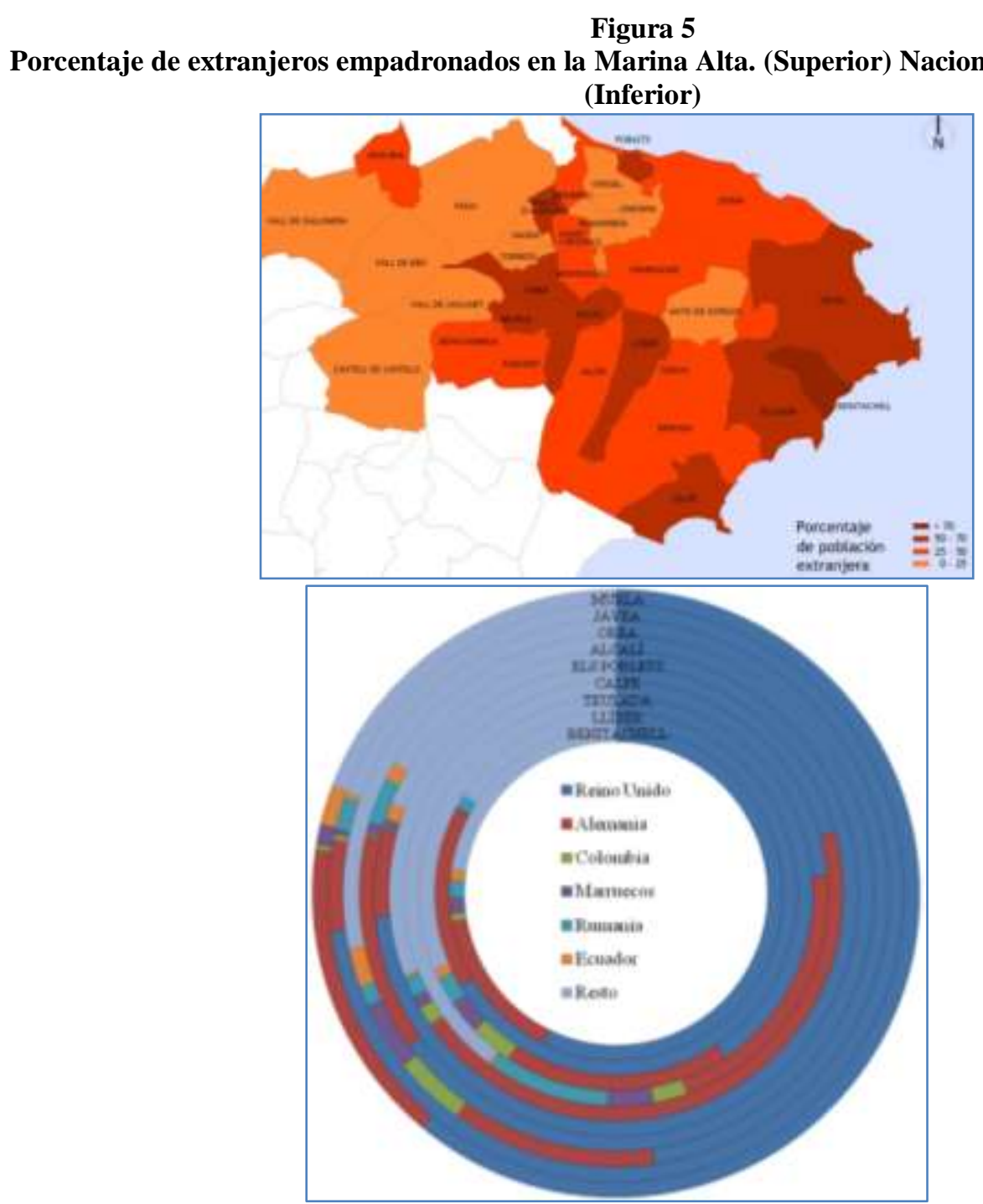

Fuente: Elaboración propia a partir del Padrón municipal de 2010, INE.

El caso del Baix Segura es más elocuente de este proceso, ya que tanto la expansión urbanística como la acogida de extranjeros incrementan sus valores muy considerablemente de modo paralelo. Aunque los municipios más poblados son Torrevieja (101.091 habitantes) y Orihuela (87.113 habitantes), por su nivel económico y administrativo, - ambos centros de polaridad comarcal, según la Estrategia Territorial de la Comunidad Valenciana ${ }^{27}$-, la relación entre población extranjera empadronada y población autóctona, destaca a San Fulgencio, Rojales y la Algorfa como poblaciones en las que los primeros superan a los segundos con un 78 por ciento para el primer caso, un 76 por ciento en el segundo caso y un 71 por ciento en el tercer caso. Particularmente en el caso de San Fulgencio, de 12.144 habitantes empadronados, 9.421 son extranjeros. Sin embargo, según el cuadro 8, se observa cómo son muchos los municipios en los

\footnotetext{
${ }^{27}$ Decreto 1/2011, de 13 de enero, del Consell, por el que se aprueba la Estrategia Territorial de la Comunitat Valenciana. Se puede consultar en http://cma.gva.es/web/indice.aspx?nodo=77495\&idioma=C
} 
que se supera el 50 por ciento de población extranjera en el Padrón municipal destacando también Algorfa (71\%), Daya Vieja (69\%) y San Miguel de Salinas (64\%).

Figura 6

Incremento de superficie en la Marina Alta. Superficie artificializada 1990-2006
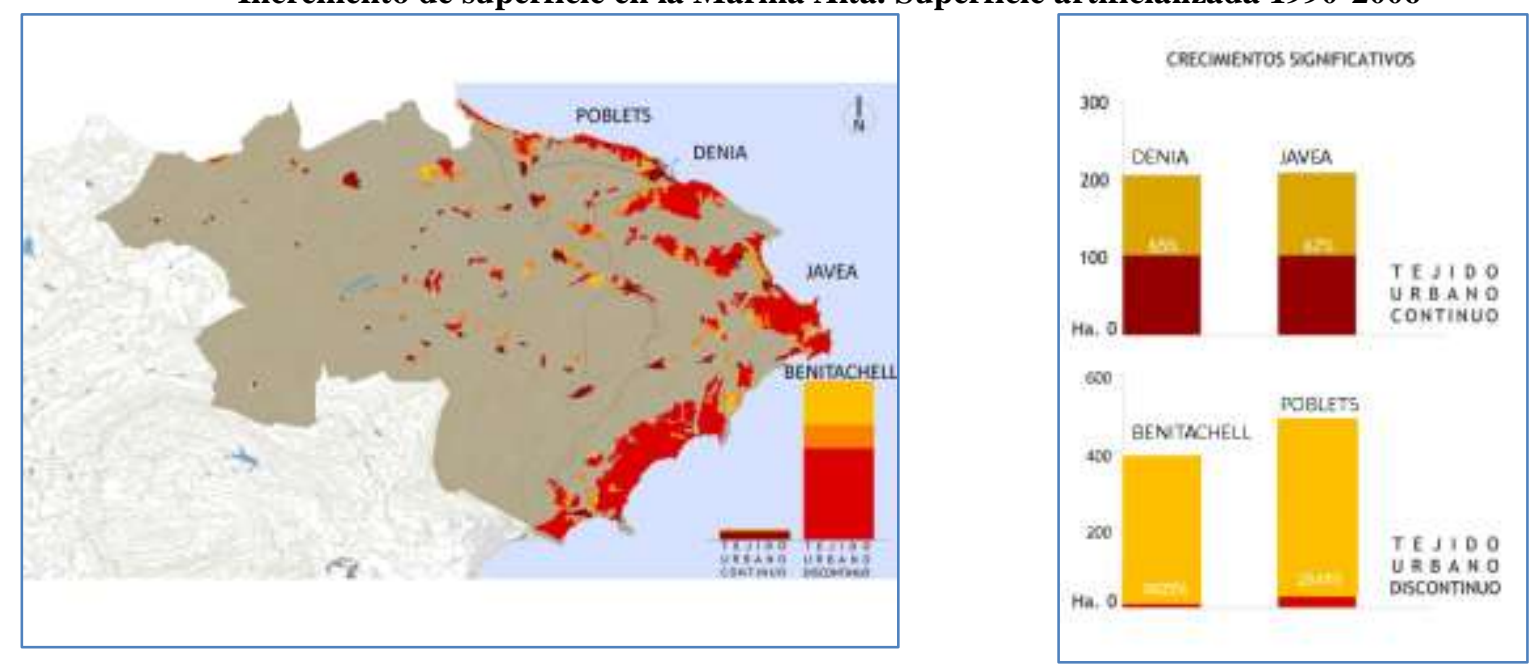

Fuente: Elaboración propia a partir del proyecto CORINE Land Cover.

Entre las principales nacionalidades de procedencia en el conjunto de la comarca se encuentra la británica seguida de la alemana, a excepción de Torrevieja, donde la diversidad de habitantes extranjeros sugiere la existencia de un panorama migratorio complejo (cuadro 8 y figura 7).

\section{Cuadro 8}

Municipios con mayor presencia extranjera empadronada y sus nacionalidades, en la comarca de la Vega Baja. Año 2010

\begin{tabular}{|c|c|c|c|c|c|c|c|c|}
\hline \multirow[b]{2}{*}{ Municipio } & \multicolumn{3}{|c|}{2010} & \multicolumn{5}{|c|}{ Procedencia } \\
\hline & Extranjeros & $\begin{array}{c}\text { Total } \\
\text { habitante } \\
\text { s }\end{array}$ & $\begin{array}{c}\% \\
\text { Extr }\end{array}$ & $\begin{array}{l}\text { Reino } \\
\text { Unido }\end{array}$ & $\begin{array}{l}\text { Alemani } \\
\text { a }\end{array}$ & $\begin{array}{l}\text { Marruec } \\
\text { os }\end{array}$ & Rumanía & Colombia \\
\hline Torrevieja & 53332 & 101091 & $53 \%$ & 12725 & 3812 & 3050 & 2150 & 1958 \\
\hline San Fulgencio & 9421 & 12144 & $78 \%$ & 6187 & 1430 & 272 & 103 & 12 \\
\hline Rojales & 15851 & 20953 & $76 \%$ & 8840 & 1563 & 404 & 58 & 28 \\
\hline Benijófar & 2395 & 4004 & $60 \%$ & 1339 & 261 & 51 & 12 & 2 \\
\hline San Miguel de las Salinas & 5186 & 8057 & $64 \%$ & 3310 & 693 & 70 & 49 & 21 \\
\hline Algorfa & 3209 & 4537 & $71 \%$ & 2681 & 177 & 1 & 8 & 6 \\
\hline Daya Vieja & 478 & 696 & $69 \%$ & 358 & 15 & 0 & 0 & 2 \\
\hline
\end{tabular}

Fuente: Elaboración propia a partir del Padrón municipal de 2010, INE.

Desde el punto de vista del incremento de suelo construido entre los años 1990 y 2006, se advierte un incremento notable tanto de tejido urbano continuo como de tejido urbano discontinuo. En el primer caso destacan municipios como Benferri cuyo crecimiento ha sido de un 204 por ciento, pasando de 18,3 ha construidas a 55,7 ha - o Catral con un incremento del 184,2 por ciento - de 35,9 ha a 102,03 ha- En el estudio del tejido urbano discontinuo, son muy notables los municipios de San Miguel de Salinas o San Fulgencio con incrementos del 3179,00 por ciento y 1549,63 por ciento respectivamente, que en superficies van desde las 12,8 ha a las 420,0 ha, y desde las 25,00 ha a las 412,3 ha.

Por tanto, tras poner en relación las variables ocupación del suelo artificializado y presencia de habitantes noreuropeos en las comarcas de la Marina Alta y del Baix Segura, se considera pertinente estudiar de manera pormenorizada los casos en los que existiendo los mayores incrementos de 
tejido urbano discontinuo en el periodo estudiado se produce un aumento notable en la población noreuropea según la población autóctona empadronada. Dado que esta situación se observa de modo evidente en las dos comarcas litorales mencionadas de la provincia de Alicante - la Marina Alta y el Baix Segura, los casos de estudio son los de los municipios de Poblenou de Benitachell y San Miguel de Salinas.

Figura 7

Porcentaje de extranjeros empadronados en el Baix Segura. (Superior) Nacionalidades de procedencia (Inferior)
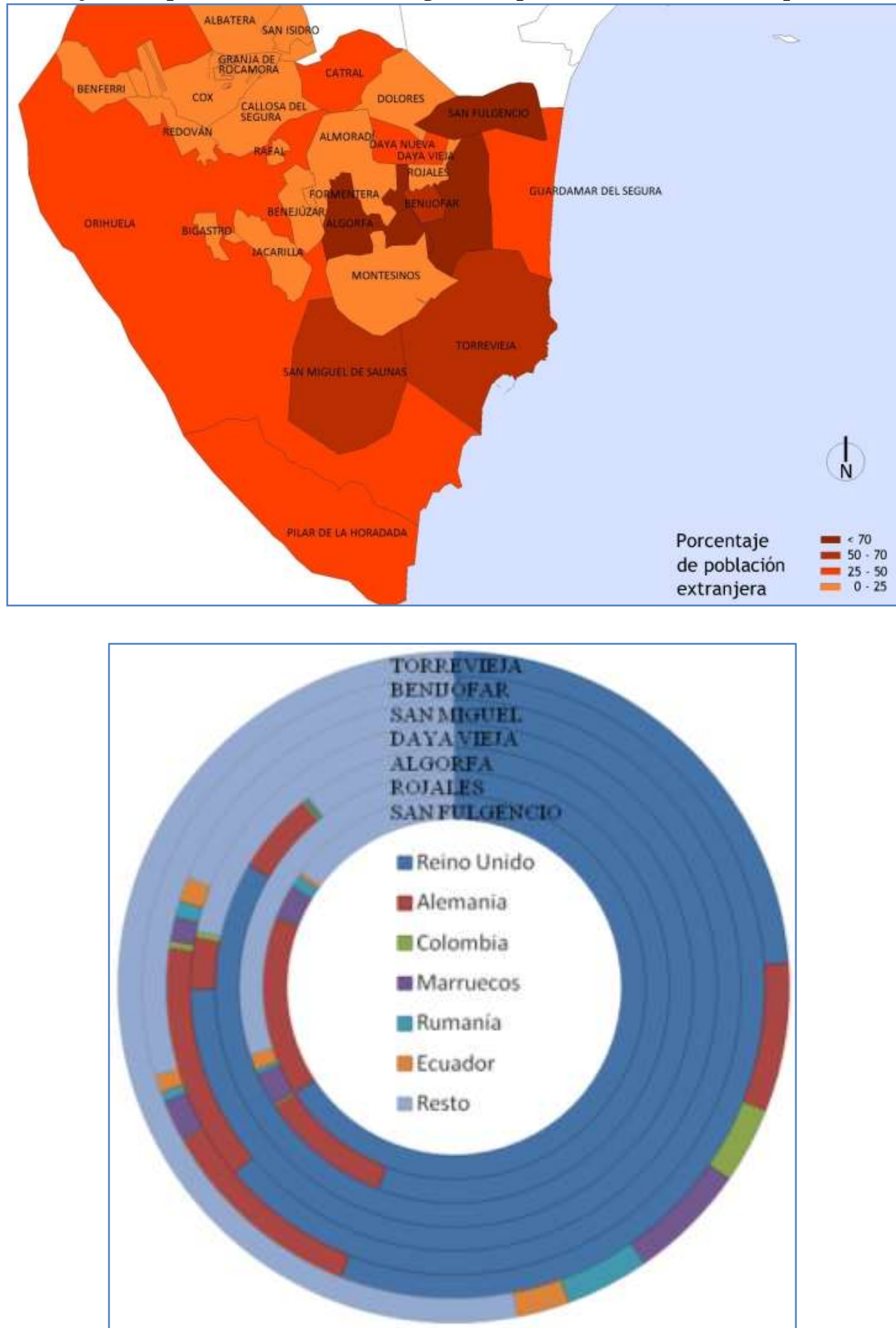

Fuente: Instituto Nacional de Estadística. Padrón municipal a 1-01-2010. Elaboración propia. 
Figura 8

Incremento de superficie en el Baix Segura. Superficie artificializada 1990-2006
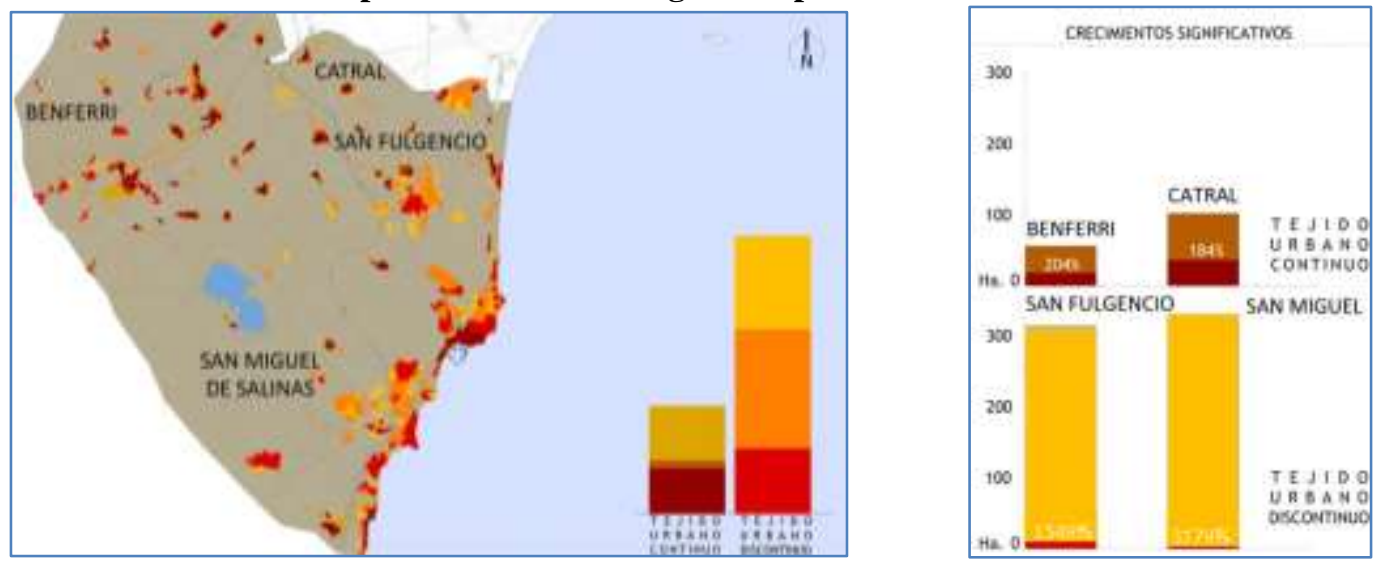

Fuente: Elaboración propia a partir del Proyecto CORINE Land Cover.

\section{Modelo urbanístico de los municipios de Poblenou de Benitachell y San Miguel de Salinas}

\section{Poblenou de Benitachell}

Benitachell es un municipio de la Marina Alta, que limita con Jávea por el norte, con Teulada por el sur y con Gata de Gorgos por el Oeste, manteniendo continuidad con todos ellos existen importantes bolsas de asentamiento donde se localizan urbanizaciones de vivienda aislada. Su estructura urbana está configurada por un núcleo histórico que da origen al municipio y asentamientos discontinuos recientes que se forman por la construcción de urbanizaciones. El núcleo tradicional se encuentra situado en el interior, a $3 \mathrm{~km}$ del mar Mediterráneo, y su término municipal cuenta con $2 \mathrm{~km}$ lineales de costa - una costa brava y quebrada con acantilados que alcanzan en algunos puntos los 100 metros sobre el nivel del mar-. En dicho término municipal se encuentran las urbanizaciones de Castellons, les Fonts, Poble Alcásar, Calistros y, la de mayor antigüedad, la Cumbre del Sol.

Figura 9

Poblenou de Benitatxell

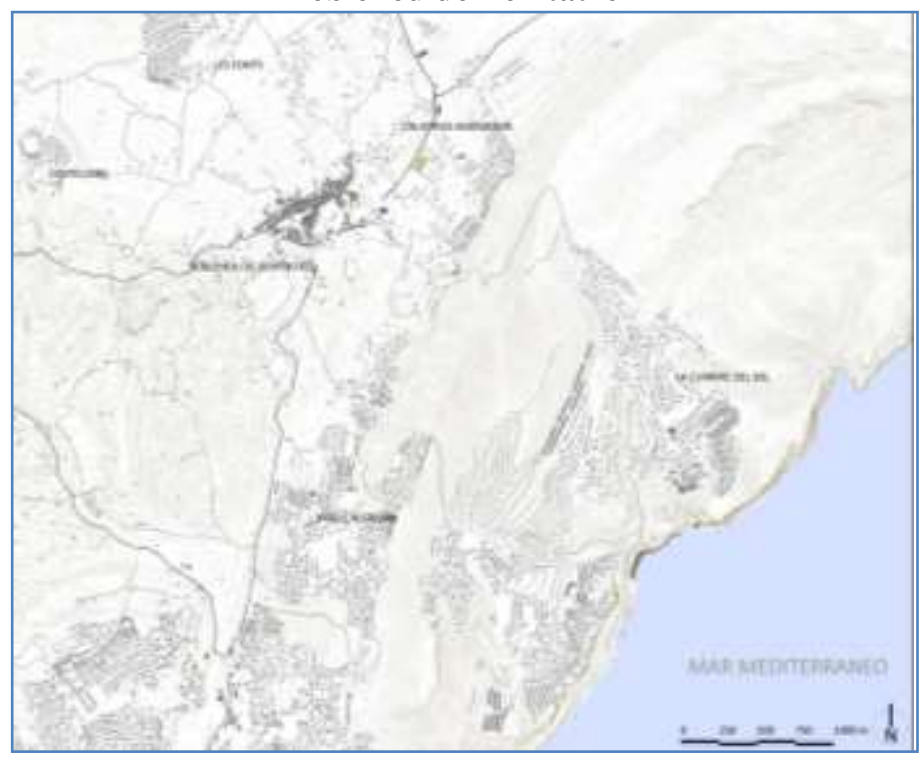

Fuente: Elaboración propia a partir de cartografía BCV05 (1:5.000) Terrasit (ICV) 
Con la finalidad de estudiar la evolución urbana del municipio, es preciso remontarse a 1984 para comprender mejor su proceso de transformación. Según la fotografía aérea del CNIG de $1984^{28}$ - Centro Nacional de Información Geográfica-, se constata que es en este momento cuando se inicia la construcción de la urbanización la Cumbre del Sol. El proceso de esta construcción se acomete en diversas fases: en la primera la ocupación del suelo no supera las 9,6 ha y la presencia de noreuropeos es inferior a la de españoles; en la segunda fase, se produce un crecimiento considerable alcanzando en el año 2001 las 225,6 ha de suelo urbanizado, lo que supone un crecimiento de 216 hectáreas en 15 años y casi la mitad del territorio municipal urbanizado. En este periodo cambia por completo la estructura demográfica de la población y se duplican los noreuropeos empadronados, ya que, si bien en 1984 Benitachell contaba con 518, en el año 2001 ya eran más del doble (1.077). Durante el periodo que va desde el año 2001 al 2006 se ralentiza el crecimiento de la superficie urbanizada, incrementándose en 18 ha durante este periodo; sin embargo, la población extranjera que reside en el municipio aumenta hasta alcanzar 2.762 habitantes, lo que supera considerablemente a la población española (1.514 habitantes). Finalmente, durante la cuarta fase de crecimiento, se produce el crecimiento más importante teniendo en cuenta el corto espacio temporal en el que sucede, ya que, desde 2006 hasta la actualidad, el tejido urbano discontinuo aumenta 191 ha, ocupando un total de 436,2 hectáreas y quedando una gran porción de ellas aún por edificar. (figura 10)

Figura 10

Evolución de Poblenou de Benitatxell

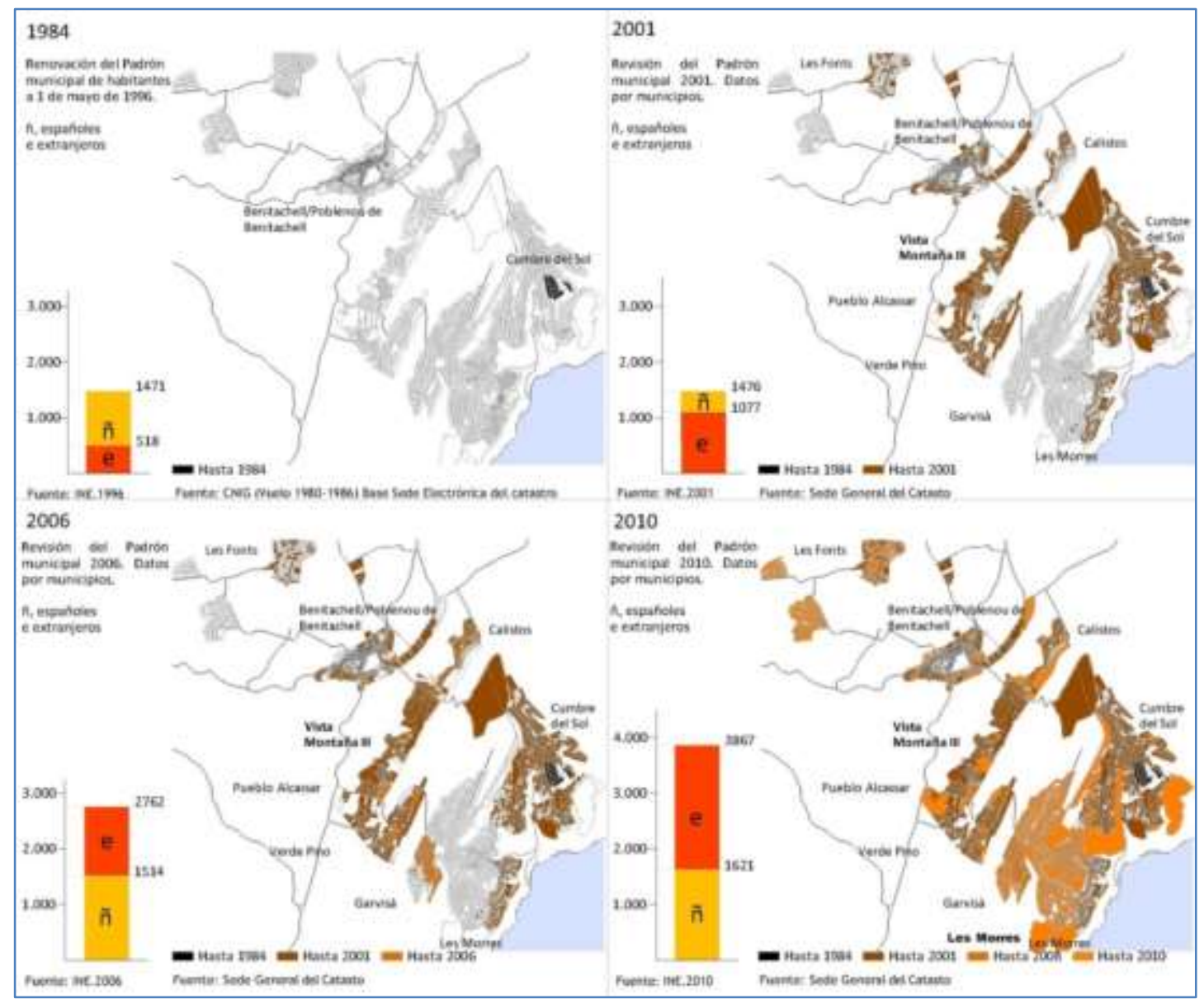

Fuente: Elaboración propia a partir de la cartografía de la Sede Electrónica del Catastro y SIOSE.

\footnotetext{
${ }^{28}$ Datos obtenidos del Instituto Geográfico Nacional (IGN) descargados del CNIG a través del siguiente enlace http://centrodedescargas.cnig.es/CentroDescargas/index.jsp
} 
La identificación y localización de los noreuropeos en el municipio, supone una ardua tarea, ya que Benitachell no está dividido en distritos censales y todo el municipio es un único distrito. De este modo, aun sabiendo que el crecimiento de la superficie construida va acompañado de una mayor presencia de noreuropeos empadronados, es necesario localizar la residencia de los miembros del colectivo. Para llevar a lograr este objetivo, se inicia un proceso de búsqueda de información en las Páginas Blancas, con el fin de relacionar a los noreuropeos con sus lugares de residencia. La información que se puede obtener de las Páginas Blancas es accesible y ofrece la relación: nombre, teléfono y dirección postal. Los habitantes noreuropeos poseen un único apellido y este hecho facilita la distinción de la población según su procedencia. Tras representar el lugar de residencia de la población noreuropea se obtiene que el 98 por ciento de reside en urbanizaciones localizadas en la periferia, entre las que destaca la Cumbre del Sol seguida de la urbanización de Les Fonts. (cuadro 9 y figura 11)

\begin{tabular}{|c|c|c|c|}
\hline \multirow{2}{*}{\multicolumn{2}{|c|}{ banizacione }} & \multicolumn{2}{|l|}{ Cuadro 9} \\
\hline & & $\begin{array}{l}\text { Españoles } \\
\text { (unidades de } \\
\text { vivienda) }\end{array}$ & $\begin{array}{l}\text { Noreuropeos } \\
\text { (unidades de } \\
\text { vivienda) }\end{array}$ \\
\hline & $\begin{array}{c}\text { Cumbre del } \\
\text { Sol }\end{array}$ & 8,00 & 220,00 \\
\hline & Les Fonts & 3,00 & 112,00 \\
\hline & Calistos & 4,00 & 57,00 \\
\hline & Acázar & 6,00 & 48,00 \\
\hline & $\begin{array}{l}\text { Golden } \\
\text { Valley }\end{array}$ & 0,00 & 28,00 \\
\hline & La Joya & 0,00 & 14,00 \\
\hline
\end{tabular}

Fuente: Elaboración propia a partir de Páginas Blancas 2010.

Figura 11

Panorámica del paisaje de Benitachell

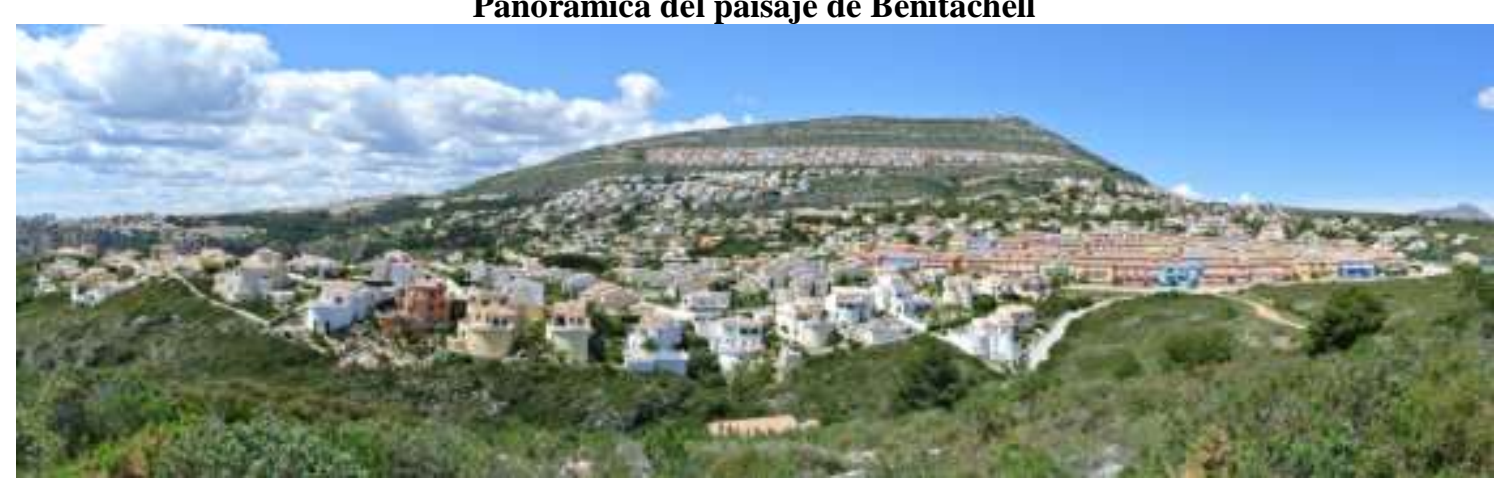

Fuente: Laura Domínguez.

En ambos casos se observa una configuración similar en cuanto a la estructura parcelaria. Las urbanizaciones se encuentran conectadas a la estructura urbana municipal mediante vías secundarias de trazado orgánico que se ajusta a la topografía. El acceso a las parcelas se produce a través de bucles o de fondos de saco. La dimensión de la parcela media es de aproximadamente $900 \mathrm{~m}^{2}$, en la Cumbre del Sol y de $800 \mathrm{~m}^{2}$ en el caso de Les Fonts.

Sin embargo, se constatan diferencias, en cuanto a la organización, urbanización y parcelación de las actuaciones más recientes, pues existen parcelas de $120 \mathrm{~m}^{2}$ en contraste con los tamaños medios mencionados. 
También se introduce la edificación adosada en lugar de la aislada, se ordena según edificaciones alineadas a viario en lugar de con retranqueos o se alcanzan las tres y cuatro plantas frente a la construcción con una o dos plantas anterior.

Figura 12

Mapa de alturas de una parte de la Urbanización Cumbre del Sol

\begin{tabular}{|c|c|}
\hline & $\begin{array}{l}\text { Cumbre } \\
\text { del Sol }\end{array}$ \\
\hline Parcelas urbanizadas & 1886 \\
\hline Parcelas edificadas & 846 \\
\hline Parcelas sin edificar & 1040 \\
\hline $\begin{array}{l}\text { Superficie Suelo SIN } \\
\text { EDIFICAR }\end{array}$ & 117,32 \\
\hline TOT AL (ha.) & 263,24 \\
\hline $\begin{array}{l}\text { Dimensión de } \\
\text { parcela máxima } \\
\left(\mathrm{m}^{2}\right)\end{array}$ & 188467 \\
\hline $\begin{array}{l}\text { Dimensión de } \\
\text { parcela mínima }\left(\mathrm{m}^{2}\right)\end{array}$ & 98 \\
\hline $\begin{array}{l}\text { Dimensión de } \\
\text { parcela media }\left(\mathrm{m}^{2}\right)\end{array}$ & 911,58 \\
\hline Densidad (viv/ha.) & 17,11 \\
\hline $\begin{array}{l}\text { Alturas de de la } \\
\text { edificación }\end{array}$ & \\
\hline 1 & 929 \\
\hline 2 & 570 \\
\hline 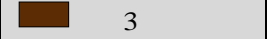 & 132 \\
\hline 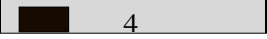 & 46 \\
\hline
\end{tabular}

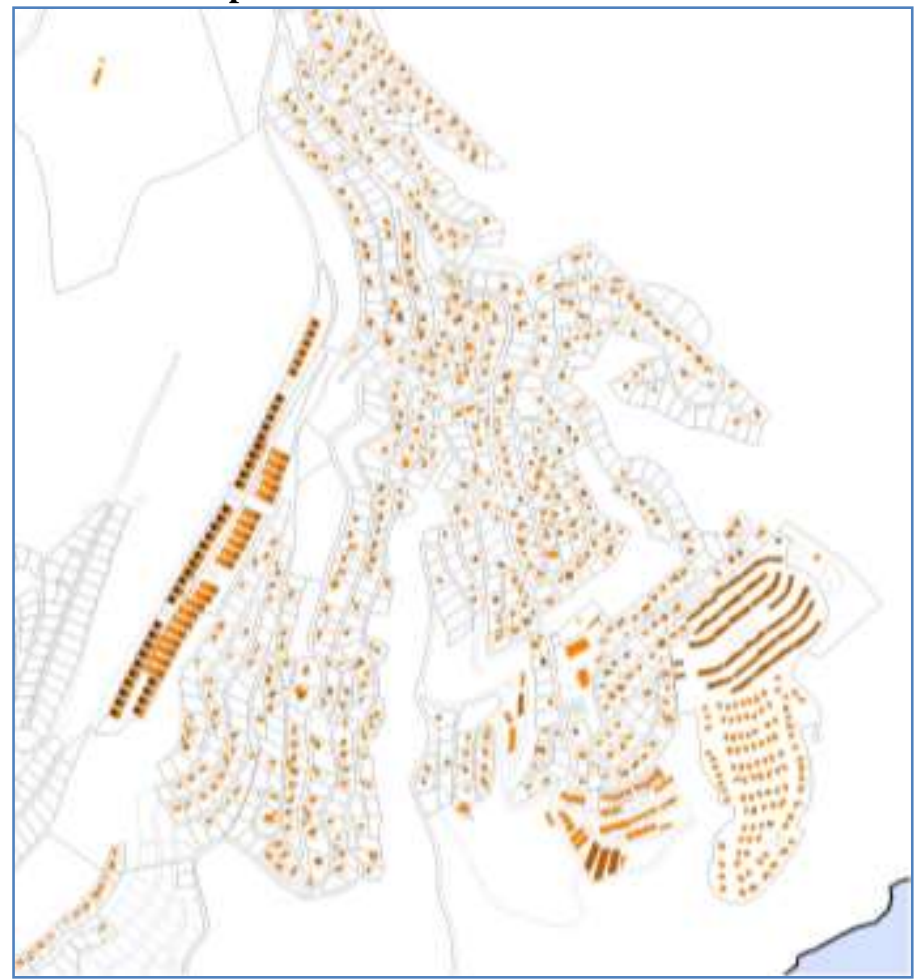

Fuente: Elaboración propia a partir de la información disponible en la Sede Electrónica del Catastro.

Figura 13

Mapa de alturas de la Urbanización de Les Fonts

\begin{tabular}{|c|c|}
\hline & Les Fonts \\
\hline Parcelas urbanizadas & 226 \\
\hline Parcelas edificadas & 151 \\
\hline Parcelas sin edificar & 75 \\
\hline $\begin{array}{l}\text { Superficie Suelo SIN } \\
\text { EDIFICAR }\end{array}$ & 5,76 \\
\hline $\begin{array}{l}\text { SUPERFICIE } \\
\text { TOT AL (ha.) }\end{array}$ & 16,02 \\
\hline $\begin{array}{l}\text { Dimensión de } \\
\text { parcela máxima } \\
\left(\mathrm{m}^{2}\right)\end{array}$ & 4935 \\
\hline $\begin{array}{l}\text { Dimensión de } \\
\text { parcela mínima }\left(\mathrm{m}^{2}\right)\end{array}$ & 158 \\
\hline $\begin{array}{l}\text { Dimensión de } \\
\text { parcela media }\left(m^{2}\right)\end{array}$ & 718,69 \\
\hline Densidad (viv/ha.) & 9,43 \\
\hline $\begin{array}{l}\text { Alturas de de la } \\
\text { edificación }\end{array}$ & \\
\hline$\square \quad 1$ & 130 \\
\hline$\square \quad 2$ & 21 \\
\hline
\end{tabular}

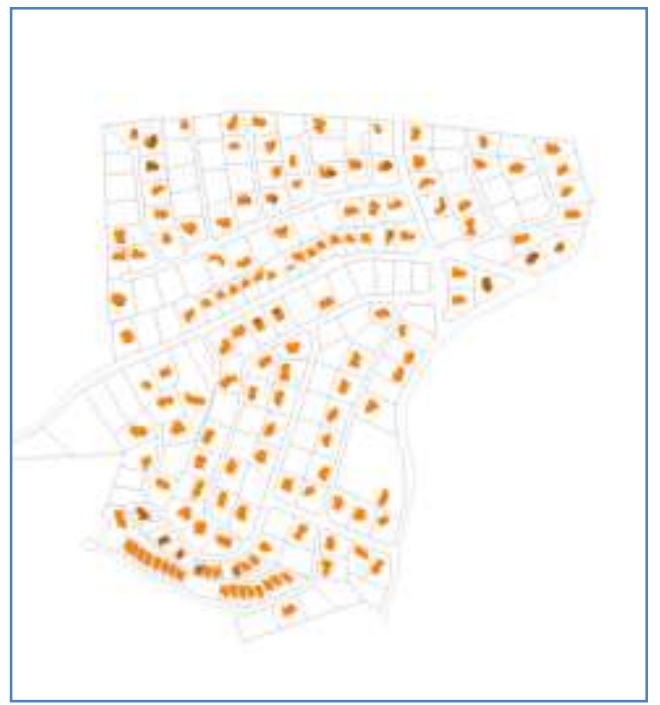

Fuente: Elaboración propia a partir de la base de la información disponible en la Sede Electrónica del Catastro. 
Además, las dotaciones deportivas (piscinas) pasan a ser comunitarias en lugar de privativas como ocurre en las parcelas de más dimensión. En definitiva, no se trata únicamente de una reducción de dimensiones en la parcela sino de un conjunto de transformaciones que configura tejidos y paisajes diferentes en este territorio (figuras 12 y 13 ).

\section{San Miguel de Salinas}

Localizado en el prelitoral de la costa sur alicantina, entre Torrevieja y Pilar de la Horadada, el municipio de San Miguel de Salinas limita con Orihuela — capital de la comarca - al sur, al noreste con Torrevieja y al norte con Los Montesinos. El municipio presenta una ubicación privilegiada, siendo la población más elevada de la comarca. San Miguel de Salinas se configura a partir de un núcleo tradicional rodeado de una serie de agregaciones parcelarias que conforman urbanizaciones.

Particularmente, esta población ha pasado de ocupar 12,8 ha de suelo discontinuo edificado en 1990 a las 112,7 ha en el año 2006 — según CORINE Land Cover 1990-2006 - y, de modo paralelo a este importante desarrollo urbanístico, el número de noreuropeos empadronados supera en un 70 por ciento a los españoles registrados.

Desde 1984 hasta la actualidad, San Miguel de Salinas ha crecido de forma progresiva aunque no constante. Si bien en 1984 únicamente existían 5,5 ha de superficie ocupada y en el año 2001 la ocupación del suelo alcanzaba las 5,9 ha; en tan solo 5 años más, la superficie artificializada se incrementa en 15,5 ha ocupando un total de 27 ha en 2006. Sin embargo, la etapa de mayor cambio se produce en el corto espacio temporal 2006 - 2010, cuando el crecimiento registrado alcanza las 183,7 ha de terreno urbanizado, ocupando el territorio según el modelo de urban sprawl. (figura 14)

Figura 14

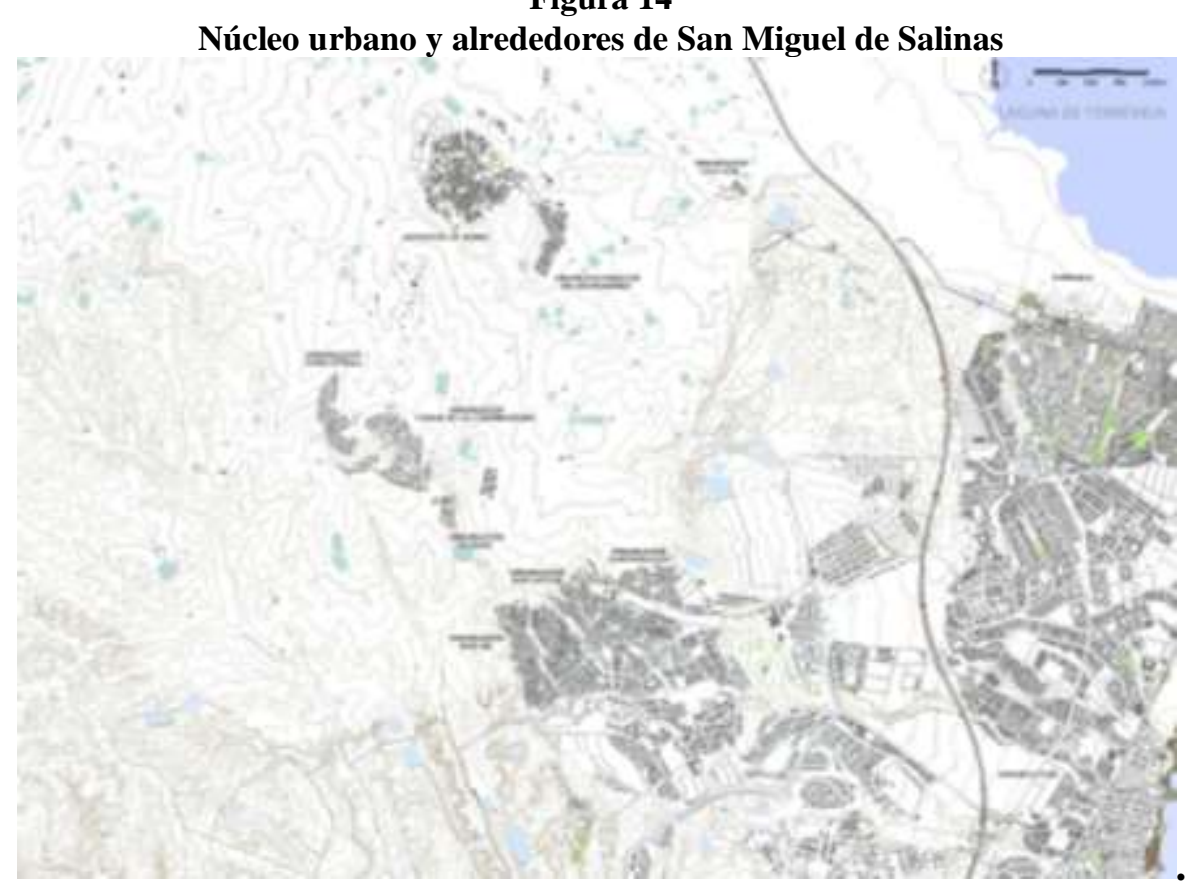

Fuente: Elaboración propia a partir de cartografía BCV05 (1:5.000) Terrasit (ICV)

De modo paralelo al crecimiento descrito, la población empadronada experimenta cambios en el mismo lapso de tiempo, pues si bien en 1984 la cantidad de españoles triplicaba a la de extranjeros, el incremento progresivo de noreuropeos en el municipio es tal que la población 
extranjera duplica a la población autóctona en 2001, se supera el millar de foráneos empadronados en 2006 y en 2010 la población extranjera pasa a triplicarse (figura 15).

Figura 15

Evolución de crecimiento de San Miguel de Salinas y su población

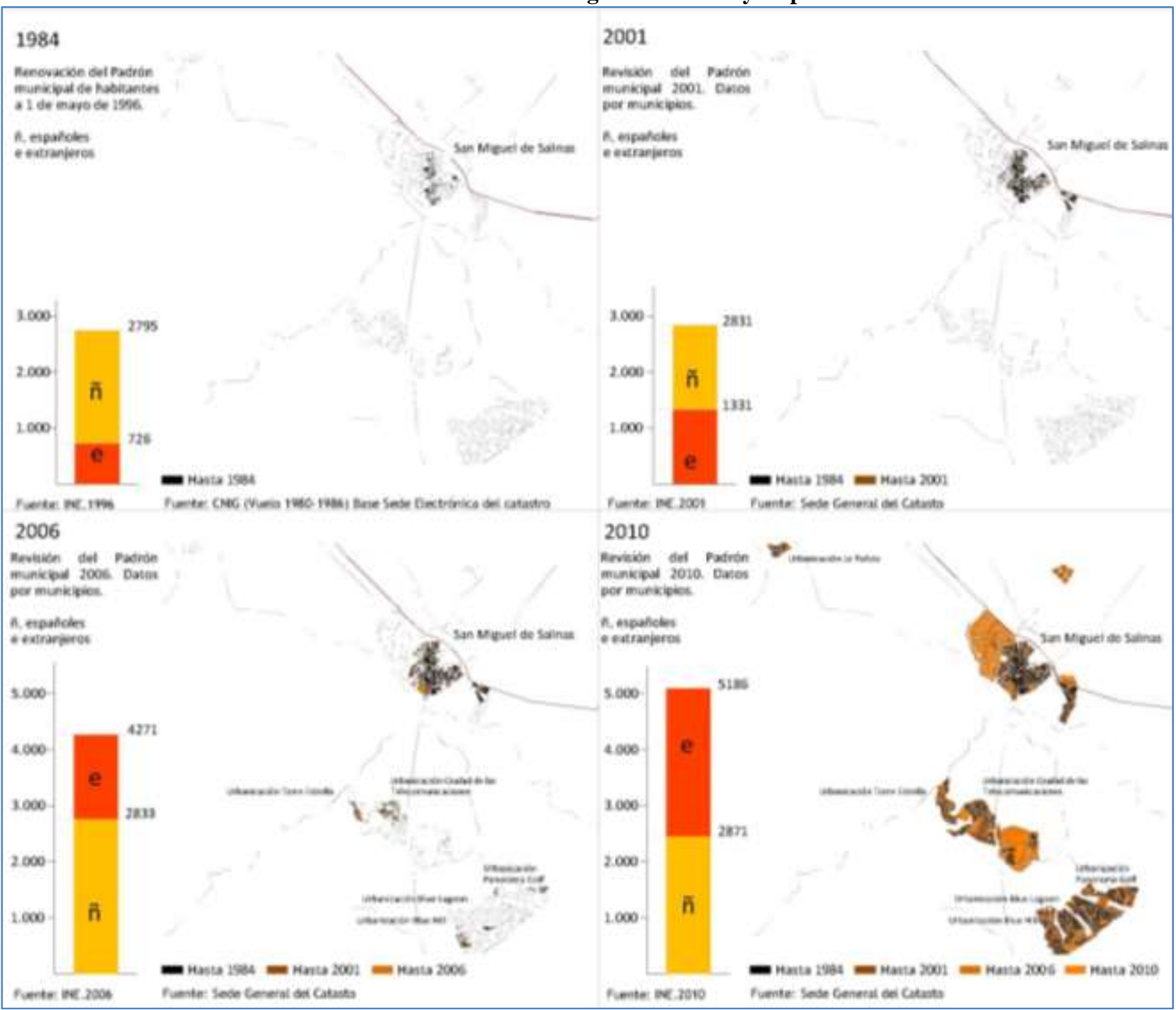

Fuente: Elaboración propia a partir de cartografía de la Sede Electrónica del Catastro.

En definitiva, a la vista de los datos se constata cómo, de manera paralela, se produce un considerable incremento en la superficie construida y una progresiva inversión de la dinámica de población. Con el fin de profundizar sobre los espacios en los que residen los noreuropeos en este municipio, al igual que en el caso de Benitachell, se analizan los datos recogidos en las Páginas Blancas. De este modo, se identifica la urbanización Blue Lagoon como la que alberga un mayor porcentaje de población extranjera (37\%), seguida de la Ciudad de las Comunicaciones con un 27 por ciento y de Las Filipinas con un 19 por ciento, además, tras el recuento, podemos decir que la presencia española es escasa (cuadro 10).

De este modo, puede afirmarse que existe un numeroso colectivo noreuropeo asentado en las urbanizaciones de San Miguel de Salinas y pueden estudiarse sus particulares cualidades urbanísticas. 
La urbanización de Ciudad de las Comunicaciones es una de las primeras en construirse (1985). Situada en un promontorio alejado $1,5 \mathrm{~km}$ de la ciudad, su nombre deriva del hecho de ser entregadas a los miembros de la Comunication Postal Workers Union. Su construcción se produce en cuatro fases de las que todavía quedan parcelas libres. Actualmente, entre los residentes hay algunos españoles en la primera fase, junto con escandinavos, alemanes y holandeses, aunque sin duda, el grupo más numeroso es el de los ciudadanos de Reino Unido.

\section{Cuadro 10}

Presencia de extranjeros sobre las Urbanizaciones de San Miguel de Salinas

\begin{tabular}{|c|c|c|}
\cline { 2 - 3 } \multicolumn{1}{c|}{} & $\begin{array}{l}\text { Españoles } \\
\text { (unidades de } \\
\text { vivienda) }\end{array}$ & $\begin{array}{l}\text { Noreuropeos } \\
\text { (unidades de } \\
\text { vivienda) }\end{array}$ \\
\hline $\begin{array}{c}\text { Ciudad de las } \\
\text { Comunicaciones }\end{array}$ & 6,00 & 102,00 \\
\hline Blue Lagoon & 11,00 & 138,00 \\
\hline Torre Estrella & 3,00 & 18,00 \\
\hline Filipinas & 5,00 & 65,00 \\
\hline Torre Azul & 3,00 & 28,00 \\
\hline Aldea Monte & 1,00 & 20,00 \\
\hline
\end{tabular}

Fuente: Elaboración propia a partir de Páginas Blancas 2010.

Su estructura viaria responde a un trazado orgánico y reticular que se adapta a las condiciones impuestas por la orografía. La parcelación, que desde el proyecto planteaba con dimensiones superiores a los $500 \mathrm{~m}^{2}$, alcanza de media los $650 \mathrm{~m}^{2}$, lo que da lugar a una densidad edificada de 17,11 viviendas por hectárea. La distribución del interior de cada parcela es similar en todos los casos ya que se disponen viviendas unifamiliares aisladas de una o dos alturas, predominando los casos de una única altura- con una piscina por parcela. Cabe destacar que la anchura de los viales mantiene una dimensión uniforme de 10 metros, lo que permite la doble circulación viaria y la existencia de aceras de un metro en cada lado. (figuras 16 y 17)

Figura 16

Fotografía aérea de San Miguel de Salinas

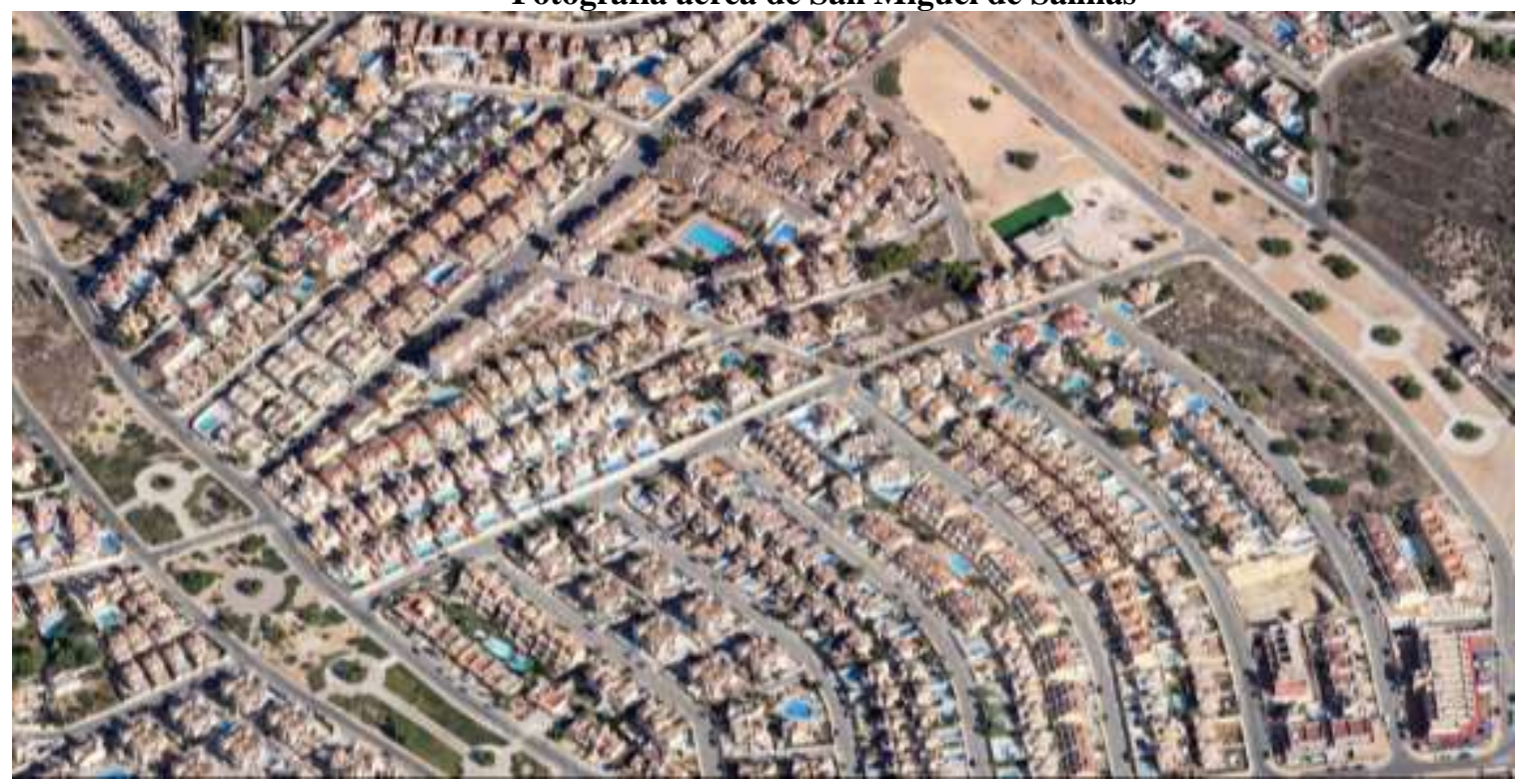

Fuente: Bing Maps.

En contraste con esta configuración urbana, la urbanización Blue Lagoon, de construcción más reciente y consolidada desde 2009, cuenta casi exclusivamente con población noreuropea y, al igual que en Ciudad de las Comunicaciones, su principal procedencia es Reino Unido. 
Figura 17

Ordenación parcelaria, edificaciones y alturas en Ciudad de las Comunicaciones

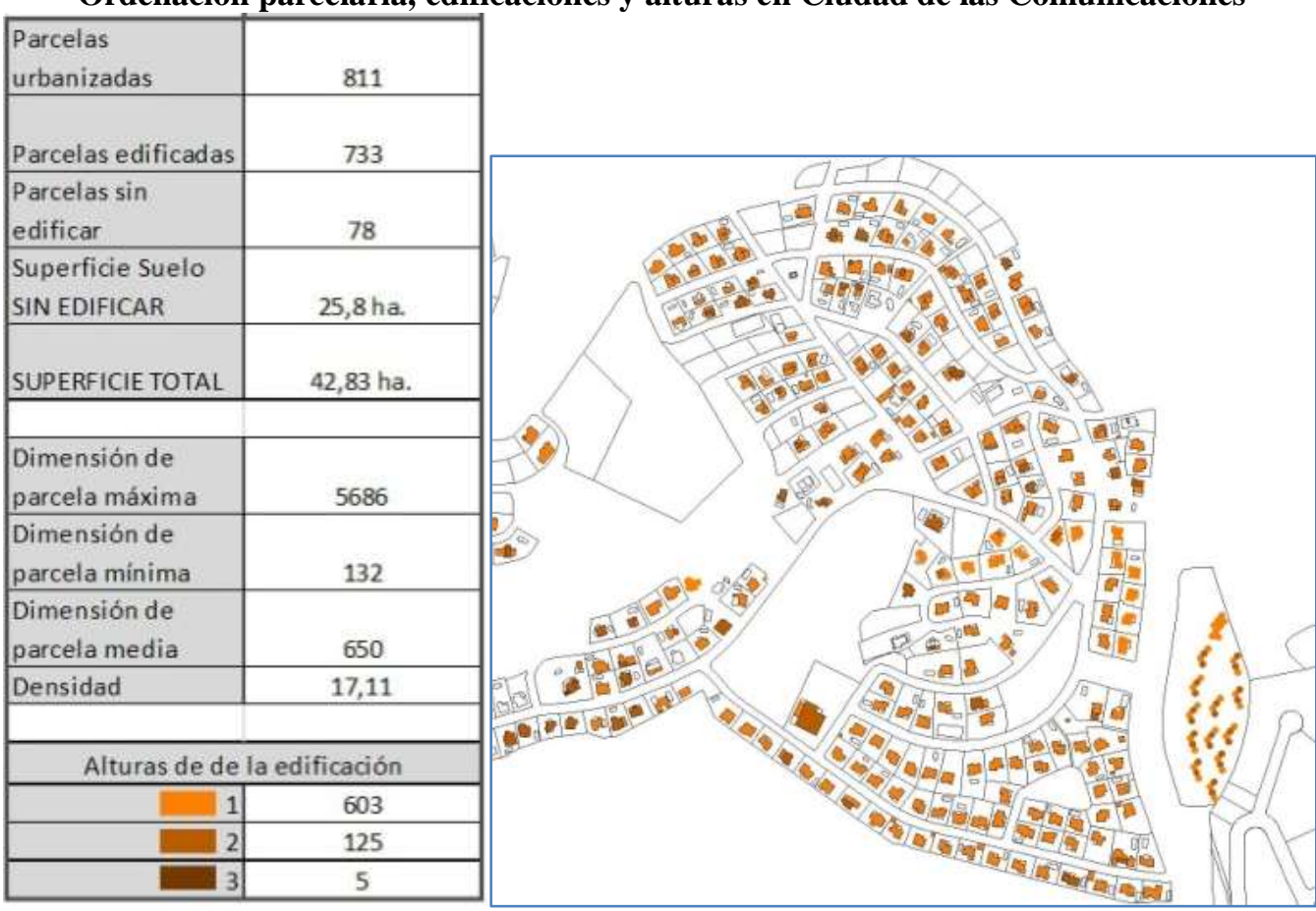

Fuente: Elaboración propia a partir de la cartografía de la Sede Electrónica del Catastro.

Entre las principales cualidades urbanísticas de esta urbanización se encuentran su trazado viario basado en la disposición de retícula irregular a pesar de estar situada en un terreno plano y dimensiones de parcela en torno a los $450 \mathrm{~m}^{2}$ - aunque hay casos en los que son menores de 100 $\mathrm{m}^{2}$ - La tipología predominante es la de vivienda unifamiliar aislada aunque aparecen algunas agrupaciones de viviendas — de una o dos alturas y excepcionalmente hasta tres - que comparten espacio libre y piscina comunitaria. (figura 18)

Figura 18

Ordenación parcelaria, edificaciones y alturas en Blue Lagoon

\begin{tabular}{|c|c|c|}
\hline $\begin{array}{l}\text { Parcelas } \\
\text { urbanizadas }\end{array}$ & 663 & 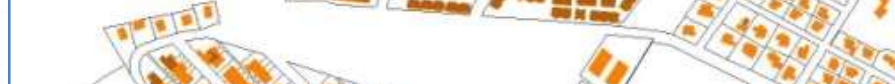 \\
\hline Parcelas edificadas & 652 & \\
\hline $\begin{array}{l}\text { Parcelas } \sin \\
\text { edificar }\end{array}$ & 11 & 1 \\
\hline $\begin{array}{l}\text { Superficie Suelo } \\
\text { SIN EDIFICAR }\end{array}$ & 5,0 ha. & 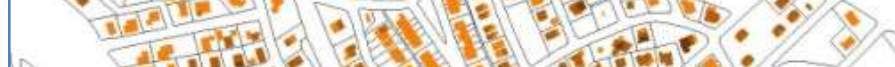 \\
\hline $\begin{array}{l}\text { SUPERFICIE TOTAL } \\
\text { (ha.) }\end{array}$ & 28,81 ha. & 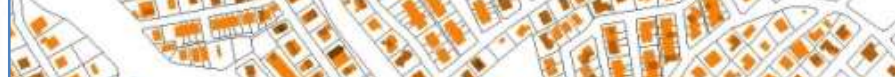 \\
\hline $\begin{array}{l}\text { Dimensión de } \\
\text { parcela máxima }\end{array}$ & 5349 & (15) \\
\hline $\begin{array}{l}\text { Dimensión de } \\
\text { parcela minima }\end{array}$ & 98 & - -250 \\
\hline $\begin{array}{l}\text { Dimensión de } \\
\text { parcela media }\end{array}$ & 440 & 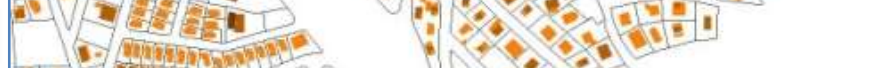 \\
\hline Densidad & 22,63888889 & 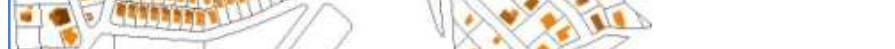 \\
\hline edificación & & \\
\hline 1 & 319 & \\
\hline 2 & 307 & \\
\hline 3 & 26 & $\rightarrow-0.00$ \\
\hline
\end{tabular}

Fuente: Elaboración propia a partir de la cartografía de la Sede Electrónica del Catastro. 


\section{Conclusiones}

El estudio sobre la relación entre el incremento en la ocupación del suelo y el aumento de población noreuropea en la provincia de Alicante, entre 1990 y 2010, evidencia la existencia de espacios urbanos en los que ambos procesos resultan coincidentes.

Se ha detectado que, en la provincia de Alicante, los mayores incrementos de tejido urbano discontinuo en la franja $2 \mathrm{~km}-5 \mathrm{~km}$ están asociados a presencia de población noreuropea que alcanza valores realmente altos en el total poblacional de algunos municipios. Concretamente, las comarcas costeras más al norte y al sur de la provincia alojan los valores más elevados de ambos parámetros $\mathrm{y}$, aunque en general la distribución de ambos valores en el conjunto provincial se produce de forma heterogénea, sí se constata que el fenómeno se repite más frecuentemente en las comarcas litorales frente a las de interior. Por este motivo, al estudiar con mayor detalle los municipios del litoral y el prelitoral de la provincia se determina que, tanto el crecimiento de ocupación de suelo como la presencia de noreuropeos, se produce de forma más evidente en la comarca más al norte — la Marina Alta — y en la situada más al sur —el Baix Segura-.

A escala local, los municipios de ambas comarcas donde una elevada presencia de noreuropeos coincide con importantes crecimientos en el mismo periodo de tiempo son: Benitachell, Teulada y Calpe en la Marina Alta y San Miguel de Salinas, San Fulgencio y la Algorfa en el Baix Segura. Por tanto, los enclaves de mayor interés para realizar un estudio pormenorizado acerca de cómo se producen los asentamientos en los que reside la población noreuropea resultan ser Poblenou de Benitachell y San Miguel de Salinas, donde se producen importantes crecimientos de tejido urbano discontinuo durante las dos últimas décadas -3805 por ciento y 3179 por ciento respectivamente - y ambos con un porcentaje de población extranjera empadronada de más del 60 por ciento.

Concretamente, del estudio pormenorizado en cuanto a la configuración urbanística de las urbanizaciones en las que se localiza la mayor presencia de población noreuropea se constatan algunas cuestiones comunes a los asentamientos de ambos municipios.

En primer lugar, los asentamientos escogidos por los noreuropeos para residir se encuentran preferentemente en municipios del prelitoral localizados en la franja entre 2 y $5 \mathrm{~km}$ de distancia de la costa y alejados de los núcleos tradicionales. Esta cuestión es un posible indicador de la prevalencia de factores económicos o sociales sobre la localización junto al mar o en entornos asociados a la imagen local tradicional en el momento de elegir un lugar de residencia con fines turísticos.

En segundo lugar, las formas de agregación son similares y la densidad de la edificación en los asentamientos estudiados no supera en ningún caso las 23 viviendas por hectárea. Este valor, que puede calificarse de bajo, repercute positivamente en cuanto a que estas urbanizaciones poseen buena capacidad para su integración paisajística aunque el mismo dato tiene una valoración negativa en cuanto a que requiere demasiada cantidad de suelo para la cantidad de población que aloja.

En tercer lugar, la configuración del espacio libre en estas urbanizaciones resulta muy característica, pues más allá de la inexistencia de espacio público diferente al que ocupan las calles de acceso a parcelas, el espacio libre en parcelas está destinado al uso privado individual o comunitario. En este sentido, se observa una progresiva tendencia a la construcción de espacios 
libres comunitarios en las fases de más reciente construcción. Conviene matizar que las urbanizaciones de Benitachell, al norte de la provincia, tienen un carácter parcelario más homogéneo donde el espacio privado tiene una estructura común basada en piscina y jardín individual - para el caso de las urbanizaciones más antiguas - mientras que las recientes comparten zonas comunes ajardinadas y piscina; lo mismo ocurre en San Miguel de Salinas, al sur, aunque con unas dimensiones inferiores de parcela que inciden negativamente en la imagen del paisaje urbano que se genera, ya que se perciben espacios edificados sin áreas verdes y con menor capacidad de integración.

Finalmente, y aunque es evidente que existen diferencias importantes entre el tamaño de la parcelación con que se construyen las urbanizaciones del norte — en Benitachell — y del sur en San Miguel de Salinas - lo que sí coincide es la reducción progresiva del tamaño de parcela en las sucesivas fases de construcción de las urbanizaciones de ambos casos. Se observa que las parcelas más recientes cuentan con un tamaño que en ocasiones es cuatro veces inferior al de las parcelas más antiguas. Sí es cierto que existe una diferencia que no puede atribuirse únicamente a la configuración urbanística de los asentamientos ya que la existencia de la segregación según nacionalidades, localizando al colectivo alemán preferentemente en las urbanizaciones del norte frente al británico al sur, no parece responder únicamente a cuestiones relacionadas con la organización espacial del asentamiento.

Por tanto, a la vista de los resultados, se constata la relación directa que existe entre la creciente actividad que se genera en base al turismo residencial de noreuropeos y el incremento en la ocupación del suelo costero que no solamente se transforma con fines turísticos sino que lo hace con una configuración característica en base a tipologías arquitectónicas de baja densidad y espacios libres privados.

\section{Bibliografía}

AGENCIA EUROPEA DE MEDIO AMBIENTE. Proyecto Corine Land Cover 1990, 2000, 2006. Instituto Geográfico Nacional. [En línea] Madrid. <http://centrodedescargas.cnig.es/CentroDescargas/buscar.do>. [25 de octubre de 2010].

AGENCIA EUROPEA DE MEDIO AMBIENTE. Urban sprawl in Europe - The Ignored Challenge. EEA Report (10). 2006.[En línea] <http://www.eea.europa.eu/publications/eea_report_2006_10/eea_report_10_2006.pdf>. [4 de octubre de 2013].

ARTIGUES, Antoni Albert y RULLÁN, Onofre. Nuevo modelo de producción residencial y territorio urbano disperso (Mallorca, 1998-2006). Scripta Nova. Revista electrónica de geografía y ciencias sociales, Actas del IX Coloquio Internacional de Neocrítica, 2007. [En línea]. Porto Alegre: Universidad de Río Grande do Sul, 28 de mayo - 1 de junio de 2007, <http://www.ub.es/geocrit/9porto/artigues.htm> [10 de septiembre de 2013]

CUTILLAS, Ernesto. El incremento de la población extranjera en la provincia de Alicante. Los contrastes en su distribución espacial. Investigaciones Geográficas núm.41 (septiembrediciembre). Alicante: Universidad de Alicante, 2006, p. 85-104. 
CUTILLAS, Ernesto. Jubilados europeos en la provincia de Alicante: la segregación residencial en la ocupación del territorio. En: Despoblación, envejecimiento y territorio: un análisis sobre la población española. López Trigal, L.; Abellán García, A.; Godenau, D.; (coord.). León: Universidad de León, Área de Publicaciones, 2009, p. 441-454.

DELGADO, Carmen. Vivienda secundaria y turismo residencial como agentes de urbanización y segregación territorial en Cantabria. Scripta Nova. Revista Electrónica de Geografía y Ciencias sociales. [En línea]. Barcelona: Universidad de Barcelona, 15 de julio de 2008, vol. XII, núm. 261 <http://www.ub.es/geocrit/sn/sn-269.htm>. [12 de septiembre de 2013].

DOMINGO, Andreu y SABATER, Albert. El empadronamiento de la población extranjera en los municipios catalanes de 2004 a 2008. Scripta Nova. Revista Electrónica de Geografía y Ciencias Sociales. [En línea]. Barcelona: Universidad de Barcelona, 1 de diciembre de 2010, vol. XIV, no 344. <http://www.ub.es/geocrit/sn/sn-344.htm>. [12 de septiembre de 2013].

ESTRATEGIA TERRITORIAL DE LA COMUNITAT VALENCIANA. Decreto 166/2011, de 4 de noviembre, del Consell de la Generalitat Valenciana.

GREENPEACE. Destrucción a toda costa. Informe sobre la situación del litoral español. [En línea]. 2006. <http://www.greeenpeace.es>. [20 de enero de 2014].

HALL, Colin Michael y MÜLLER, Dieter. K. Tourism, mobility and second homes: between elite landscape and common ground. Clevedon: Channel View Books., 2004, 304 p.

HUETE, Raquel. Turistas que llegan para quedarse. Una explicación sociológica sobre la movilidad residencial. Alicante: Publicaciones Universidad de Alicante. 2009.

HUETE, Raquel y MANTECÓN, Alejandro. Political participation of British and German residents in Spain: The case of San Miguel de Salinas, Alicante. La participación política de los residentes británicos y alemanes en España: El caso de San Miguel de Salinas, Alicante (51), 2012, p. 81-93.

INSTITUTO GEOGRÁFICO NACIONAL (IGN) http://www.ign.es/ign/main/index.do

INEBASE: Padrón Municipal 1990 y 2006. En: Instituto Nacional de Estadística. INEbase. [En línea] Madrid. <http://www.ine.es/inebmenu/mnu_cifraspob.htm>. [10 de enero de 2014].

INDEC, Ministerio de Economía. Censo Nacional de Población, Vivienda y Hogares, 2001. [18 de marzo de 2014]

INSTITUTO VALENCIANO DE ESTADÍSTICA (IVE). La Comunidad Valenciana 2010, [En línea] Valencia <http://www.ive.es>. [10 de septiembre de 2013]

JURDAO, Francisco. España en venta. Compra de suelo por extranjeros y colonización de campesinos en la Costa del Sol. Madrid: Ayuso, 1979.

MANTECÓN, Alejandro; HUETE, Raquel y MAZÓN, Tomás. Las urbanizaciones "europeas”. Una investigación sobre las nuevas sociedades duales en el Mediterráneo. Scripta Nova. Revista Electrónica de Geografía y Ciencias Sociales. [En línea]. Barcelona: Universidad de Barcelona, 10 de octubre de 2009, vol. XIII, n 301. <http://www.ub.es/geocrit/sn/sn-301.htm>. 
MARTÍ, Pablo y NOLASCO, Almudena. Un caso paradigmático de sprawl: la costa de la provincia de Alicante. ACE: Architecture, City and Environment = Arquitectura, Ciudad y Entorno [En línea]. 2012, año 7, núm. 20 Octubre. p.173-198 <http://www-cpsv.upc.es/ace/Articles_n20/articles_pdf/ACE_20_SE_25.pdf >. [ISSN: 18864805].

MARTÍ, Pablo y NOLASCO, Almudena. La expansión urbanística reciente de la costa alicantina, una realidad constatable. En: Urbanismo expansivo de la Utopía a la Realidad XXII Congreso de Geógrafos Españoles. Alicante: Universidad de Alicante, 2011. p. 367-378

MAZÓN, Tomás; HUETE, Raquel y MANTECÓN, Alejandro. Migraciones Internacionales de Retirados (MIR): Discursos de la sociedad de acogida ante los estilos de vida de los jubilados europeos residentes en la provincia de Alicante. En: Actas del X Congreso sobre Población Española. Pamplona: Universidad de Navarra, 2006.

MAZÓN, Tomás y ALEDO, Antonio.: El turismo inmobiliario en la provincia de Alicante: Análisis y propuestas. Alicante: Patronato Provincial de Turismo Costa Blanca, Diputación de Alicante. 1996

MAZÓN, Tomás y ALEDO, Antonio. El dilema del turismo residencial: ¿turismo o desarrollo inmobiliario. En: Mazón, T.; Aledo, A. (eds.): Turismo residencial y cambio social. Nuevas perspectivas teóricas y empíricas. Alicante: Aguaclara. 2005. p.13-30

MAZÓN, Tomás. La insostenibilidad del turismo residencial. En: Antropología y turismo: claves culturales y disciplinares. México: Plaza y Valdés, 2007.

NAVALÓN, Rosario. Planeamiento urbano y turismo residencial en los municipios litorales de Alicante. Alicante: Instituto de Cultura Juan Gil-Albert, 1995.

OBSERVATORIO DE LA SOSTENIBILIDAD EN ESPAÑA (OSE). Cambios de ocupación del suelo en España. Implicaciones para la sostenibilidad. [En línea] <http://www.upv.es/contenidos/CAMUNISO/info/U0637086.PDF> 2006. [4 de septiembre de 2013]

ORGANIZACIÓN MUNDIAL DEL TURISMO (OMT). Mercados emisores de turismo. Visión general y análisis de las características de los países, Madrid: Ed. Organización Mundial del Turismo, 1999, p.87

ORGANIZACIÓN MUNDIAL DEL TURISMO (OMT). Turismo. Panorama 2020, Madrid: Ed. Organización Mundial del Turismo, 2000, VII tomos.

OBSERVATORIO VALENCIANO DE LA VIVIENDA (OVV) Indicadores OVV. Demanda. Análisis población extranjera y vivienda. Informe $\mathrm{n}^{\circ} 6$. Valencia. [En línea] 2006. <http://www.cma.gva.es/webdoc/documento.ashx?id=122926>. [20 de enero de 2014]

OBSERVATORIO VALENCIANO DE LA VIVIENDA (OVV). Segunda Residencia y turismo residencial en la Comunidad Valenciana. Valencia. [En línea] 2006. <http://www.cma.gva.es/comunes_asp/documentos/agenda/cas/57806INFORME\%202\%C2\%AA\%20RESIDENCIA\%20Y\%20TURISMO.pdf>. [20 de enero de 2014] 
PIE, Ricard y ROSA, Carlos J. Turismo Líquido. Instituto Hábitat Turismo y Territorio a través de Iniciativa Digital Politécnica (UPC), Universidad Politécnica de Catalunya y Universidad de Málaga. Barcelona. 2013.

PONCE, Gabino. La fragmentación de la forma urbana en la Comunidad Valenciana. En: $L a$ ciudad fragmentada: nuevas formas de hábitat. Alicante: Universidad de Alicante, 2006, p.89130.

QUERO, Damián. La Urbanización del turismo un punto de vista clásico. Las nuevas formas del turismo. Colección Mediterráneo Económico. num 5. Almería: Ed. Caja Rural Intermediterránea, Cajamar. - Instituto de Estudios Socioeconómicos de Cajamar.

ROCA, Josep y ROMANO, Yraida. La delimitación del suelo urbanizado: el caso de la costa alicantina, España. [En línea] ACE: Architecture, City and Environment $=$ Arquitectura, Ciudad y Entorno, vol. 4, núm.12, < https://upcommons.upc.edu/revistes/handle/2099/8553 > [25 febrero 2014], p. 59-76.

TERRASIT, Infraestructura de Datos Espaciales de la Comunidad Valenciana. [En línea] http://terrasit.gva.es INSTITUTO CARTOGRÁFICO VALENCIANO.

VERA, Fernando. Turismo y urbanización en el litoral alicantino. Alicante: Instituto de Estudios Juan Gil-Albert, 1987.

STEENMANS, C (Dir.); BOSSARD, M.; FERANEC, J.; OTAHEL, J. CORINE Land Cover technical guide - Addendum 2000 Technical report.: European Environment Agency. 2000.

(C) Copyright: Laura Domínguez Martínez, 2016.

(C) Copyright: Pablo Martí Ciriquian, 2016

(C) Copyright: Almudena Nolasco Cirugeda 2016

(c) Copyright Scripta Nova, 2016.

Ficha bibliográfica:

DOMÍNGUEZ MARTÍNEZ, Laura; MARTÍ CIRIQUIAN, Pablo; NOLASCO CIRUGEDA, Almudena. Turismo residencial de extranjeros en la Costa Blanca: su manifestación territorial y estudio de casos representativos Scripta Nova. Revista Electrónica de Geografía y Ciencias Sociales. [En línea]. Barcelona: Universidad de Barcelona, 1 de noviembre de 2016, vol. XX, no 547. <http://www.ub.es/geocrit/sn/sn547.pdf>. ISSN: 1138-9788. 